\title{
BODIPYs as chemically stable fluorescent tags on synthetic glycosylation strategies towards fluorescently-labeled saccharides
}

\author{
Clara Uriel,${ }^{[a]}$ Caterina Permingeat, ${ }^{[a]}$ Juan Ventura,${ }^{[a]}$ Edurne Avellanal-Zaballa,${ }^{[b]}$ Jorge Bañuelos, ${ }^{*[b]}$ \\ Inmaculada García-Moreno, ${ }^{[c]}$ Ana M. Gómez ${ }^{*[a]}$ and J. Cristobal Lopez ${ }^{*[a]}$
}

\begin{abstract}
A series of fluorescent boron-dipyrromethene (BODIPY, 4,4-difluoro-4-bora-3a,4a-diaza-s-indacene) dyes have been designed to participate, as aglycons, in synthetic oligosaccharide protocols. As such, they served a dual purpose: first, by being incorporated at the beginning of the process (at the reducing-end of the growing saccharide moiety), they can function as fluorescent glycosyl-tags facilitating the detection and purification of the desired glycosidic intermediates, and secondly the presence of these chromophores on the ensuing compounds warrants access to fluorescently-labeled saccharides. In this context, a sought-after feature of the fluorescent dyes has been their chemical robustness. Accordingly, some BODIPY derivatives described in this work are able to withstand the reaction conditions commonly employed in the chemical synthesis of saccharides, namely, glycosylation and protecting-group manipulations. Regarding their photophysical properties, the BODIPY-labeled saccharides obtained in this work displayed remarkable fluorescence-efficiency in water, reaching quantum yield values up to $82 \%$, as well as notable lasing efficiencies and photostabilities.
\end{abstract}

\section{Introduction}

The chemical synthesis of oligosaccharides ${ }^{[1]}$ and the development of fluorescent probes ${ }^{[2]}$ are two well-recognized research areas with increasing relevance. In addition, the combination of fluorescent labels and carbohydrates for the generation of fluorescent glycoprobes has become an active topic of research in recent years. ${ }^{[3]}$ Remarkably, the interest on these assemblies could arise from -at least- two different research fields.

[a] Dr. C. Uriel, Miss C. Permingeat, Dr. J. Ventura, Dr. A. M. Gómez, Prof. J. C. López

Instituto de Química Organica General (IQOG-CSIC)

Juan de la Cierva 3, 28006 Madrid, Spain

E-mail: ana.gomez@csic.es; ic.lopez@csic.es

[b] Miss E. Avellanal-Zaballa, Dr. J. Bañuelos

Dpto. Química Física

Universidad del País Vasco (UPV/EHU),

Aptdo. 644, 48080 Bilbao, Spain

E-mail: jorge.banuelos@ehu es

[c] Prof. I. Garcia-Moreno

Instituto Química-Física "Rocasolano” (IQFR-CSIC)

Serrano 119, 28006 Madrid, Spain

Supporting information for this article is given via a link at the end of the document.
Focusing on the carbohydrate partner, the fluorescent labeling of glycans allows investigations on glycoconjugates and their interactions in biological systems at high sensitivity. ${ }^{[4,5,6]}$ Alternatively, from the fluorescent-probe standpoint, owing to the relevance that carbohydrate-receptor interactions have on a number of biological processes, ${ }^{[7]}$ a glycosyl moiety linked to a fluorophore could play a significant role as a targeting ${ }^{[8]}$ and internalizating ${ }^{[9]}$ agent for the probe, sometimes providing less cytotoxic entities. ${ }^{[10]}$

On the other hand, borondipyrromethene (BODIPY) dyes, e.g. A (Scheme 1), ${ }^{[11]}$ have emerged as remarkable fluorophores owing to their outstanding properties that include strong UV-vis absorption profiles, high fluorescence quantum yields $(\phi)$ and excellent photochemical and thermal stabilities, which has led to their use on biomaterials labeling ${ }^{[12]}$ among others. ${ }^{[13]}$

Of particular interest to us, it was that the ligation-step of the fluorophore, e.g. A, and the glycoligand, e.g. B, leading to glycoprobes, e.g. C (Scheme 1, approach $i$ ), is generally carried out as the last synthetic event, sometimes in situ, prior to their submission to the different visualization or detection techniques. ${ }^{[14]}$ Based on these precedents, we decided to investigate the feasibility of a synthetic approach to fluorescentlylabeled oligosaccharides in which the fluorescent probe, installed at the reducing-end of the growing saccharide from the beginning of the process, could additionally function as a tagging element, facilitating the visualization and detection of the synthetic saccharide intermediates (Scheme 1, approach ii).

Accordingly, in this manuscript, we disclose our investigations on an alternative approach to BODIPY-saccharide derivatives, i.e. C (Scheme 1), based on sequential glycosylation/deprotection/glycosylation events of a starting hydroxymethyl-BODIPY D, with different glycosyl donors, e.g. E (Scheme 1, approach ii).

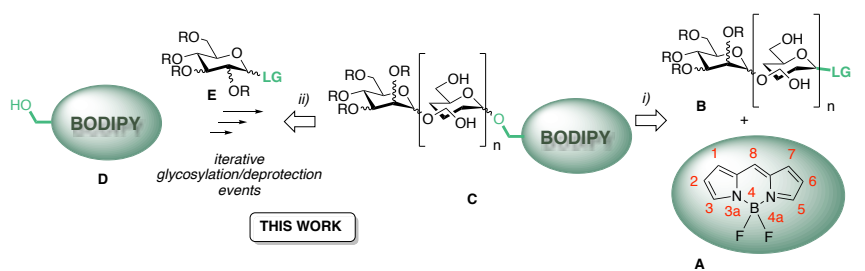

Scheme 1. i) General synthetic approach to glycoprobe $\mathbf{C}$, by ligation of a given saccharide (B) to a generic BODIPY dye (A, IUPAC numbering); and ii) proposed sequential glycosylation/deprotection/glycosylation strategy from hydroxymethyl-BODIPY D and glycosyl donors E, leading to BODIPYsaccharide structures $\mathrm{C}$ 
Consequently, our studies have focused on the search for BODIPY derivatives able to endure the reaction events commonly employed in oligosaccharide synthesis, namely, glycosylation protocols $^{[15]}$ and protecting-group manipulations. ${ }^{[16,17]}$

\section{Results and Discussion}

The present studies on the potential of BODIPY-aglycons as glycosyl tags in synthetic oligosaccharide strategies originated from an ongoing project that required a reliable synthetic route to an appropriately protected 2-hydroxy-mannopyranoside bearing a fluorophore as aglycon, and able to undergo further glycosylation at $\mathrm{O}-2$.

Accordingly, based on our experience with 1,2-methyl orthoesters $^{[18,19]}$ (MeOEs) in glycosylation, ${ }^{[20]}$ and our recent method for the efficient, one-pot, access ${ }^{[21]}$ to hydroxymethylBODIPY $1,{ }^{[22]}$ we attempted the glycosylation of the latter with MeOE 2 (Scheme 2). The glycosyl coupling, mediated by $\mathrm{BF}_{3} \cdot \mathrm{OEt}_{2}$, took place smoothly to provide BODIPYmannopyranoside 3, which upon treatment with $\mathrm{NaOMe}$ in $\mathrm{MeOH}$, produced 4,4'-methoxy-BODIPY 4. ${ }^{[23,24]}$ The latter was the result of an unwanted methoxy substitution at boron accompanying the desired de-O-benzoylation process. The use of milder saponification conditions ( $\mathrm{Et}_{3} \mathrm{~N} / \mathrm{MeOH}$, reflux) also induced methoxy substitution at boron, but left the 2-O-Bz group in mannosyl-BODIPY 5, unaffected.

Thus, even though compound $\mathbf{4}$, displayed good fluorophoric behavior, it was found of no use to us since further glycosylation attempts on 4 with MeOE donors, mediated by $\mathrm{BF}_{3} \mathrm{OEt}_{2}$, resulted in partial or total methoxy $\rightarrow$ fluor replacement at boron, thus giving rise to complex product mixtures.

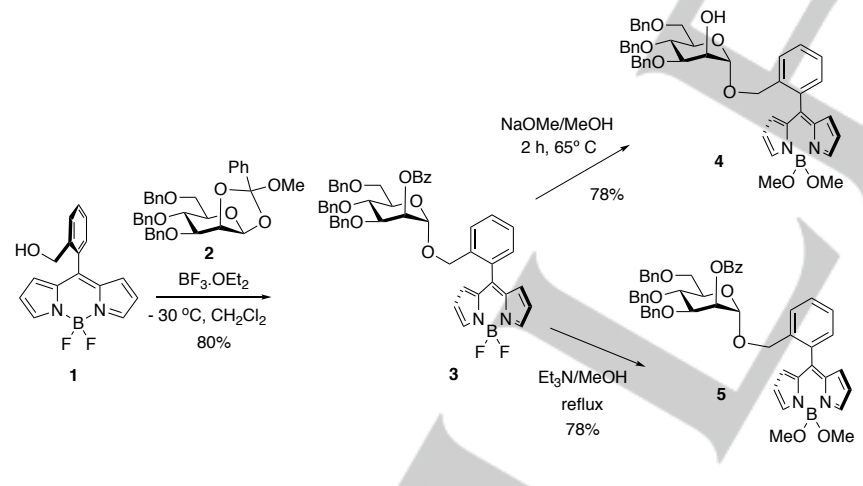

Scheme 2. Glycosylation of BODIPY 1 with MeOE 2. Attempted saponification of benzoate $\mathbf{3}$, leading to O-BODIPYs $\mathbf{4}$ and $\mathbf{5}$.

According to these results, and despite the fact that BODIPYs are typically described as "chemically robust" substrates, ${ }^{[24 b, 25,26]}$ we considered that a comprehensive screening of the compatibility of the BODIPY core with the reaction conditions employed in standard glycosylation protocols (including protecting-group manipulations) will be necessary prior to their use as fluorophoric tags in oligosaccharide synthesis.

In this context, a general survey of the scientific literature on the chemical stability of BODIPYs allowed us to identify -at least- two structural aspects with an influence on their stability. Thus, the degree of peripheral alkyl-substitution on the BODIPY core ${ }^{[27]}$ and the presence of a 8-aryl substituent, ${ }^{[28,29]}$ have for long been known to stabilize the fluorophore. On the other hand, the substitution at boron has been also identified as a key factor in the stability of BODIPYs. ${ }^{[30]}$ In this context, Yan and coworkers recognized 4,4'-diphenyl BODIPY derivatives as more stable, under acidic and basic conditions, than the corresponding 4,4'dimethyl, 4,4'-dimethoxy, or 4,4'-difluoro derivatives. ${ }^{[31]}$ More recently, reports from Vicente's and Bobadova-Parvanova's laboratories have identified 4,4'-dicyano-BODIPYs ${ }^{[32]}$ as the most stable derivatives, under acidic conditions, from a series of 4,4'disubstituted BODIPYs (including $-\mathrm{F},-\mathrm{CN}$, - $\mathrm{Ph}$, - Me and -OMe derivatives). ${ }^{[33]}$

According to these literature precedents, we selected readily available BODIPYs 6-10 ${ }^{[21]}$ to conduct our stability studies (Figure 1). Thus, derivatives 6 and 7 , and 8 and 9 differed in the substitution at boron ( $\mathrm{F}$ versus $\mathrm{CN}$ ). Compounds 8 and 9 possessed ethyl substituents at C-2 and C-6 (when compared to 6 and 7) aimed at shielding the BODIPY core towards the electrophilic reagents ${ }^{[34]}$ required in the activation of some of the glycosyl donors evaluated in this work. Additionally, since our planned studies also include the stability of these BODIPYs under hydrogenolytic conditions (necessary to deprotect benzyl groups at the glycosyl units), the hydroxyethyl derivative $\mathbf{1 0}^{[35]}$ was also considered as a non-benzylic analogue of 8 .

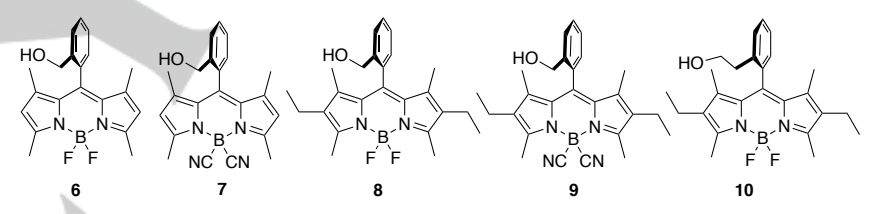

Figure 1. BODIPY Derivatives 6-10 selected for our studies.

\section{BODIPYs and protecting group manipulations}

The polyhydroxylic nature of carbohydrates and the high reactivity of the hydroxyl groups in glycosylation reactions, is the reason why in most cases, only the hydroxyl group that is meant to be glycosylated can remain unprotected during the glycosylation reaction. Therefore, protecting group manipulations have become a key issue in oligosaccharide synthesis. ${ }^{[17]}$ In this context, most of the synthetic strategies towards oligosaccharides require the handling of at least three types of orthogonal[ ${ }^{[16,17]}$ protecting groups: acyl derivatives, silyl ethers and benzyl ethers. Among them, the first two are considered "temporary" protecting groups, since they can be placed and removed several times during the synthesis, whereas benzyl ethers are regarded as "permanent" protecting groups, since they are: i) only to be removed at the very end of the saccharide preparation, ii) stable to all reaction conditions used, and iii) removable under reaction conditions that do not tamper with the integrity of the target (oligo)saccharide. ${ }^{[36]}$ For these reasons, we have evaluated the compatibility of the reaction conditions used for the deprotection of benzoyl esters, and silyl and benzyl ethers with the structural integrity of some of the BODIPYs displayed in Figure 1. 
Thus, in order to find appropriate reaction conditions for the removal of the protecting groups, we carried out our initial model studies with tert-butyldiphenylsilyl BODIPYs (BODIPY-OTBDPS), and benzoyl BODIPYS (BODIPY-OBz) (Tables 1 and 2, respectively).

Table 1. De-O-silylation of BODIPY-tert-butyldiphenylsilyl ethers (BODIPYOTBDPS) to regenerate the starting BODIPY-OHs (6-9).

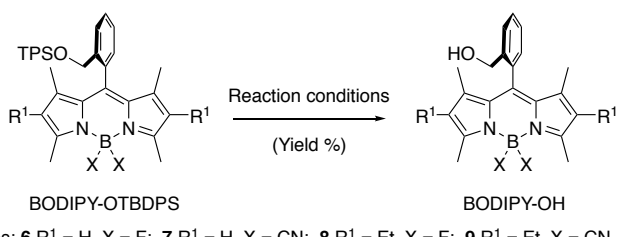

Series: $\mathbf{6} \mathrm{R}^{1}=\mathrm{H}, \mathrm{X}=\mathrm{F} ; \mathbf{7} \mathrm{R}^{1}=\mathrm{H}, \mathrm{X}=\mathrm{CN} ; \mathbf{8} \mathrm{R}^{1}=\mathrm{Et}, \mathrm{X}=\mathrm{F} ; \mathbf{9} \mathrm{R}^{1}=\mathrm{Et}, \mathrm{X}=\mathrm{CN}$

\begin{tabular}{|c|c|c|c|c|}
\hline Entry & $\begin{array}{l}\text { BODIPY- } \\
\text { OTBDPS }\end{array}$ & $\begin{array}{l}\text { Reaction } \\
\text { conditions }\end{array}$ & $\begin{array}{c}\text { BODIPY- } \\
\text { OH }\end{array}$ & Yield $[$ [c] \\
\hline$i$ & $\begin{array}{c}\text { 6- } \\
\text { OTBDPS }\end{array}$ & $\operatorname{TBAF}^{[\mathrm{a}]}$ & 6 & $48 \%$ \\
\hline$i i$ & $\begin{array}{c}7- \\
\text { OTBDPS }\end{array}$ & $\mathrm{TBAF}^{[a]}$ & 7 & $41 \%$ \\
\hline iii & $\begin{array}{c}\text { 8- } \\
\text { OTBDPS }\end{array}$ & $\operatorname{TBAF}^{[a]}$ & 8 & $38 \%$ \\
\hline iv & $\begin{array}{c}\mathbf{9 -} \\
\text { OTBDPS }\end{array}$ & TBAF $^{[a]}$ & 9 & ---- \\
\hline$v$ & $\begin{array}{c}\mathbf{6 -} \\
\text { OTBDPS }\end{array}$ & $\mathrm{HF} /$ pyridine ${ }^{[b]}$ & 6 & $52 \%\left[{ }^{[d]}\right.$ \\
\hline vi & $\begin{array}{c}7- \\
\text { OTBDPS }\end{array}$ & $\mathrm{HF} /$ pyridine ${ }^{[b]}$ & 7 & $64 \%[$ e] \\
\hline vii & $\begin{array}{c}\mathbf{8 -}^{-} \\
\text {OTBDPS }\end{array}$ & $\mathrm{HF} /$ pyridine ${ }^{[b]}$ & 8 & $78 \%$ [f] \\
\hline viii & $\begin{array}{c}\text { 9- } \\
\text { OTBDPS }\end{array}$ & $\mathrm{HF} /$ pyridine ${ }^{[b]}$ & 9 & $94 \%$ \\
\hline ix & $\begin{array}{c}\text { 6- } \\
\text { OTBDPS }\end{array}$ & $\mathrm{HCl} / \mathrm{MeOH}^{[c]}$ & 6 & $47 \%[9]$ \\
\hline$x$ & $\begin{array}{c}\text { 7- } \\
\text { OTBDPS }\end{array}$ & $\mathrm{HCl} / \mathrm{MeOH}^{[c]}$ & 7 & $93 \%$ \\
\hline$x i$ & $\begin{array}{c}\text { 8- } \\
\text { OTBDPS }\end{array}$ & $\mathrm{HCl} / \mathrm{MeOH}^{[c]}$ & 8 & \\
\hline xii & $\begin{array}{c}\mathbf{9 -} \\
\text { OTBDPS }\end{array}$ & $\mathrm{HCl} / \mathrm{MeOH}^{[c]}$ & 9 & $94 \%$ \\
\hline
\end{tabular}

[a] Tetra-n-butylammonium fluoride (TBAF) 1.5 equiv. $\mathrm{CH}_{2} \mathrm{Cl}_{2}, 0^{\circ} \mathrm{C} \rightarrow$ r.t. [b] HFpyridine (40 equiv.), THF, r.t. [c] $\mathrm{HCl} / \mathrm{MeOH}$ (1.25 M), THF, microwave irradiation, $60^{\circ} \mathrm{C}$. [d] $88 \%$ corrected yield, based on recovered starting material. [e] $87 \%$ corrected yield, based on recovered starting material. [f] $92 \%$ corrected yield, based on recovered starting material. [g] Yield obtained after treatment of the crude reaction mixture with $\mathrm{Et}_{3} \mathrm{~N}, \mathrm{BF}_{3} \mathrm{OEt}_{2}$.

As representative methods for de-O-silylation we selected three sets of reaction conditions: i) tetra- $n$-butyl ammonium fluoride (TBAF); ii) HF-pyridine in THF; and iii) $\mathrm{HCl}$ /methanol in THF, under microwave irradiation (Table 1). The best results in terms of deprotection yields and substrate stabilities were obtained with 4,4'-dicyano BODIPYs (7-OTBDPS and 9-OTBDPS) upon treatment with $\mathrm{HCl} / \mathrm{Methanol}$ under microwave irradiation (Table 1 , entries $x$ and $x i i$, respectively). Treatment with HF/pyridine furnished an excellent yield of 4,4'-dicyano-2,6-diethyl BODIPY$\mathrm{OH}$ (9) (Table 1, entry viii), and reasonable yields of BODIPYs 7 and $\mathbf{8}$ (Table 1, entries vi and vii, respectively).

From the results in Table 1, we concluded that desilylation could be successfully carried out with $\mathrm{HCl} /$ methanol in derivatives arising from 4,4'-dicyano-BODIPYs 7 and $\mathbf{9}$, and with HF/pyridine in 4,4'-dicyano-2,6-diethyl BODIPY-OH (9). In the case of silyl BODIPYs 6 and 8, treatment with $\mathrm{HCl} /$ methanol (entries ix and $x i$, respectively, Table 1) caused desilylation accompanied by nitrogen-boron cleavage on the BODIPY core leading to the corresponding, non-fluorescent, dipyrromethenes. ${ }^{[3]}$ This could be confirmed in the case of 6-OTBDPS, where treatment of the crude desilylation mixture with $\mathrm{BF}_{3} \mathrm{OEt}_{2}$ produced BODIPY 6 (Table 1, entry ix, $47 \%$ yield). ${ }^{[37]}$

Finally, in keeping with literature precedents, ${ }^{[38]}$ TBAF caused considerable decomposition of the BODIPY-core in all the derivatives (Table 1, entries $i-i v$ ).

Table 2. Saponification of BODIPY benzoates (BODIPY-OBz) to regenerate the starting BODIPY-OHs (6-9).

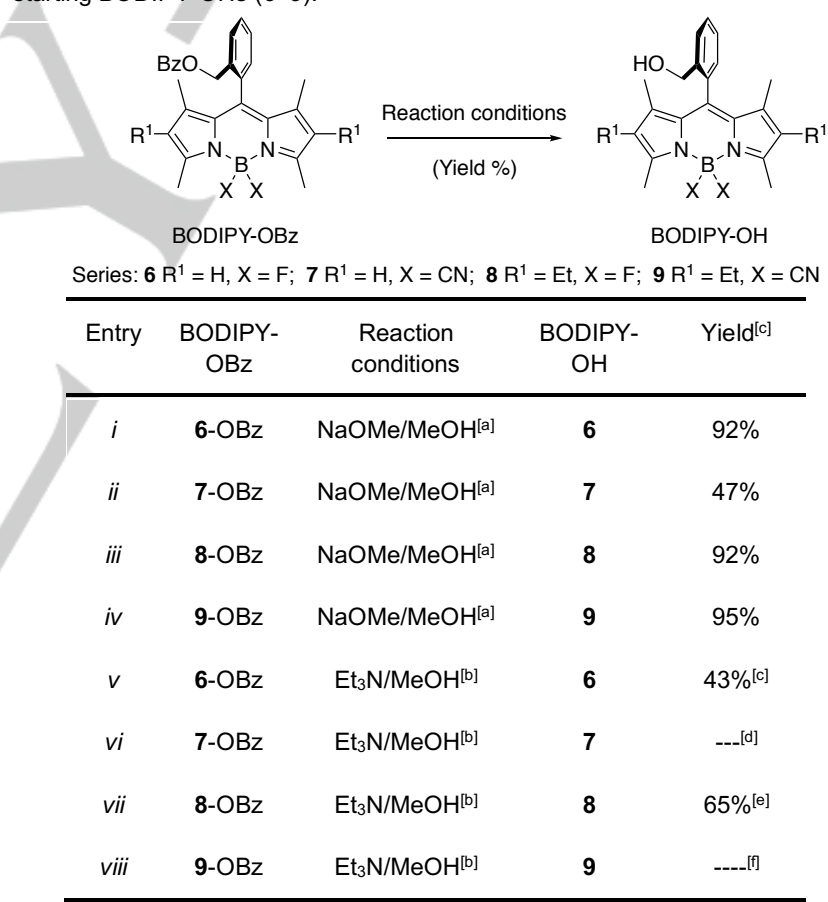

[a] Sodium methoxide in methanol, 4.4 equiv. r.t., $1-2 \mathrm{~h}$ [b] Triethylamine in methanol, reflux overnight [c] An additional $23 \%$ of the starting benzoate was recovered. [d] Complex reaction mixture containing at least five different compounds including $\mathrm{B}-(\mathrm{F}, \mathrm{OMe})$ and $\mathrm{B}(\mathrm{OMe})_{2}-\mathrm{BODIPYs}$, with or without the $\mathrm{C}$ 8 -ortho benzoyl substituent. [e] $86 \%$ corrected yield, based on recovered starting material. [f] The reaction mixture consisted on the corresponding $\mathrm{B}(\mathrm{F}, \mathrm{OMe})$ and $\mathrm{B}(\mathrm{OMe})_{2}-\mathrm{BODIPYs}$, with and without the C-8-ortho benzoyl substituent.

Analogously, de-O-benzoylation of the corresponding BODIPYOBz 6-9 derivatives was attempted under two sets of reaction conditions: i) $\mathrm{NaOMe} / \mathrm{MeOH}$ and ii) $\mathrm{Et}_{3} \mathrm{~N}$ in methanol (reflux) (Table 2). 
The best outcome in terms of reaction yields and substrate stabilities, was observed in the case of 4,4'-difluoro BODIPYs 6$\mathrm{OBz}$ and 8-OBz, and 4,4'-dicyano-BODIPY 9-OBz derivatives, upon treatment with $\mathrm{NaOMe}$ in $\mathrm{MeOH}$ (Table 2, entries $i$, iii and iv, respectively). Contrariwise, the treatment of $\mathrm{B}(\mathrm{CN})_{2}-\mathrm{BODIPY}$ with $\mathrm{Et}_{3} \mathrm{~N}$ in $\mathrm{MeOH}$ produced complex mixtures containing $\mathrm{B}(\mathrm{OMe}, \mathrm{F})-$ and $\mathrm{B}(\mathrm{OMe})_{2}$-BODIPYs, with or without the ortho-8-benzoyl group (Table 2, entries $v$-viii).

In these debenzoylation studies in basic media, regardless of the reaction conditions employed, $\mathrm{BF}_{2}$-BODIPYs, i. e. $\mathbf{6}$ and $\mathbf{8}$, were found to be more stable than the corresponding $\mathrm{B}(\mathrm{CN})_{2}$-BODIPYs (compare entry $i$ versus entry $i i$, and entries vi, vii, versus entry $i x$, Table 2). Nevertheless, de-O-benzoylation of peralkylated $\mathrm{B}(\mathrm{CN})_{2}$-BODIPY $9-\mathrm{OBz}$ proved to be successful when short reaction times and stoichiometric amounts of $\mathrm{NaOMe}$ were used.

\section{BODIPYs and glycosylation reactions}

We next set up to study the behavior of our hydroxymethylBODIPYs in glycosylation reactions. Accordingly, we have validated five types of, commonly employed, glycosyl donors: trichloroacetimidates (TCA); ${ }^{[39]}$ thioglycosides:; ${ }^{[40]}$ glycosyl bromides; ${ }^{[41]} n$-pentenyl orthoesters (NPOEs) $)^{[42]}$ and MeOEs ${ }^{[18,20]}$.

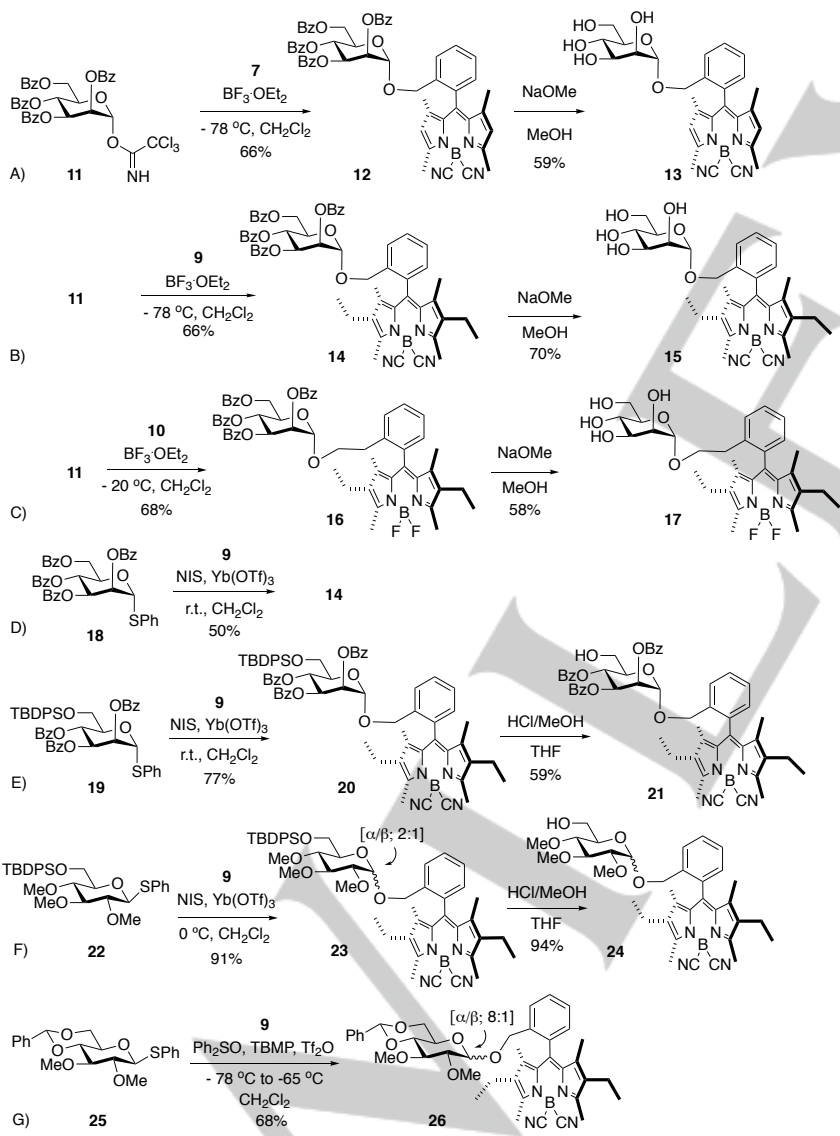

Scheme 3. Glycosylation of BODIPYs 7, 9 and 10 with glycosyl trichloroacetimidate 11, and glycosylation of BODIPY 9 with thioglycosyl donors $18,19,22$ and 25 .
The results obtained are collected in Schemes 3 and 4 .

Accordingly, trichloroacetimidate 11, reacted smoothly with 4,4'dicyano BODIPYs 7 and $\mathbf{9}$, upon activation with $\mathrm{BF}_{3} \cdot \mathrm{OEt}_{2}$ at low temperature, to give tetra-O-benzoyl mannopyranosides 12 and 14 , respectively, in moderate yields (Scheme $3 \mathrm{~A}$ and $3 \mathrm{~B}$ ). These benzoyl glycosides yielded, upon saponification with $\mathrm{NaOMe} / \mathrm{MeOH}$, tetraols 13 and 15 , respectively (Scheme $3 \mathrm{~A}$ and 3B). Likewise, glycosylation of 4,4'-difluoro-BODIPY 10 with TCA 11 at higher temperature yielded mannopyranoside 16, which upon saponification, produced tetraol glycoside 17 (Scheme 3C). Next, the glycosylation of BODIPY 9 with phenyl thioglycosides 18, 19, 22 and 25, was examined. Thus, armed and disarmed ${ }^{[43]}$ thioglycosides could be activated by treatment with NIS in the presence of $\mathrm{Yb}(\mathrm{OTf})_{3},{ }^{[44]}$ to yield BODIPY-glycosides 14, 20 and 23 in moderate to good yields (Scheme 3D,E,F, respectively), the latter being isolated as a (2:1) $\alpha / \beta$ anomeric mixture. The use of the $\mathrm{N}$-iodosuccinimide (NIS)/BF $3 \mathrm{OEt}_{2}$ system, ${ }^{[45]}$ as the promotor in the activation of the thioglycosides, caused partial replacement of $-\mathrm{CN}$ by fluoride at boron, thus yielding mixtures of the corresponding 4,4-difluoro- and 4-fluor-4'-cyano-BODIPY glycosides. The use of electrophilic NIS as promotor precluded the use of BODIPYs 6 and 7 as acceptors, owing to the nucleophilicity of the BODIPYs at positions C-2 and C-6. ${ }^{[34]}$ On the other hand, desilylation of BODIPY-glycosides 20 and $\mathbf{2 3}$, leading to the hydroxyl derivatives 21 and 24 (Scheme 3E and 3F, respectively), could be efficiently effected by treatment with $\mathrm{HCl} /$ methanol, as seen before (Table 1 , entry xii). Finally, activation of phenyl thioglycoside $\mathbf{2 5}$ with the thiophilic promotor system $\mathrm{Ph}_{2} \mathrm{SO} / \mathrm{Tf}_{2} \mathrm{O},{ }^{[46]}$ in the presence of 4-tert-butyl-2,6-dimethylpyridine (TBMP), was also possible and yielded glucoside 26 in $68 \%$ yield, as an (8:1) $\alpha / \beta$ anomeric mixture with the $\alpha$ anomer prevailing.

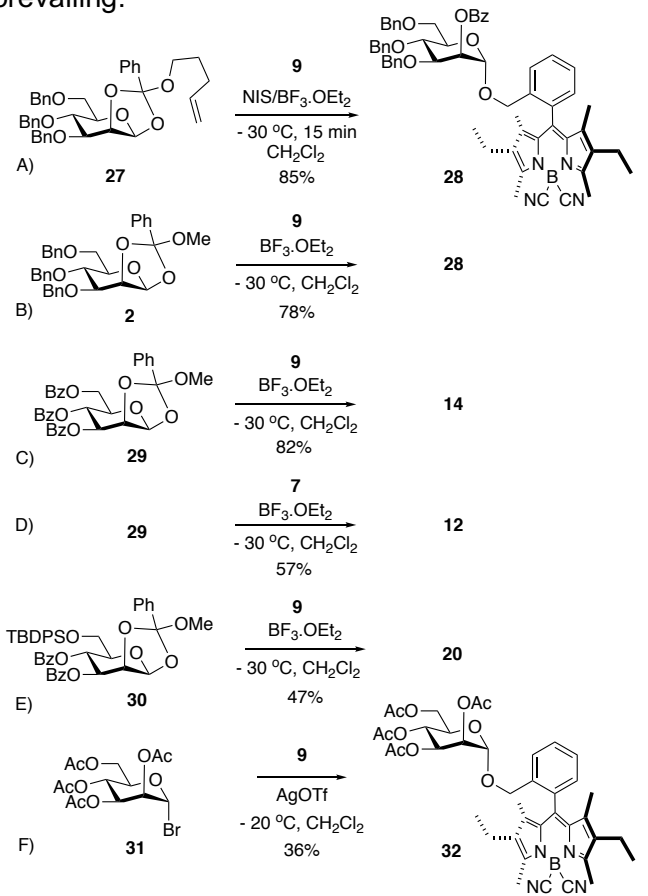

Scheme 4. NPOE 27, MeOEs 2, 29 and 30 and glycosyl bromide 31, in the glycosylation of BODIPYs 7 and $\mathbf{9}$. 
In keeping with these studies, the system $\mathrm{NIS}_{\mathrm{B}} \mathrm{BF}_{3} \cdot \mathrm{OEt} 2$ was found to successfully activate NPOE $\mathbf{2 7}$ in the glycosylation of BODIPY 9, to furnish mannopyranosyl BODIPY 28 in $85 \%$ yield (Scheme $4 \mathrm{~A})$. In this case, no $-\mathrm{CN}$ replacement by fluoride at boron was observed, probably due to the short reaction time required for the reaction to be completed (15 $\mathrm{min}$ ).

As seen earlier (Scheme 2), MeOEs could be efficiently activated by the action of $\mathrm{BF}_{3} \cdot \mathrm{OEt}_{2}$ at low temperature, and accordingly glycosyl BODIPYs 28, 14, 12 and 20 were uneventfully obtained from MeOEs 2, 29 and 30, (Scheme 4B,C,D,E). The use of AgOTf to activate glycosyl bromide 31 , was also compatible with BODIPY 9, and mannopyranosyl BODIPY 32 could be obtained, in $36 \%$ yield $(45 \%$ yield based on recovered starting material, Scheme 4F). In this case, the low yield of $\mathbf{3 2}$ was explained by a competing acetylation of the BODIPY aglycon ( $24 \%$ of BODIPYOAc 9 could be isolated).

\section{Glycosyl BODIPYs and benzyl protecting groups}

As mentioned earlier, benzyl groups play a key role on the synthesis of saccharides, since they are visualized as permanent protecting groups to be usually removed at one of the last steps of the synthetic sequence. ${ }^{[4]}$ Thus, the question of the stability of our BODIPYs, and their benzylic BODIPY-glycoside bonds under hydrogenolytic conditions became worthy of study.

In this context, previous studies had already shown that alkylated BODIPYs were stable under hydrogenolytic conditions. ${ }^{[48]}$ With these precedents in mind, we checked the stability of substituted BODIPYs 6-10, compared to that of non-alkylated BODIPY 1 (Scheme 5A). Thus, whereas the former derivatives were recovered unmodified after prolonged treatment with $\mathrm{H}_{2}$ [(35 psi), $7 \mathrm{~h}, \mathrm{Pd} / \mathrm{C}, \mathrm{MeOH} / \mathrm{CH}_{2} \mathrm{Cl}_{2}$ ], treatment of fluorescent BODIPY 1 with $\mathrm{H}_{2}$ (balloon, $\mathrm{Pd} / \mathrm{C}, \mathrm{MeOH} / \mathrm{CH}_{2} \mathrm{Cl}_{2}, 40 \mathrm{~min}$ ) caused completed disappearance of its fluorescence, thereby indicating that cleavage of the BODIPY core might had taken place (Scheme 5A). Next, we tested the stability of the benzylic-BODIPY bond in our BODIPY-glycosides by submitting perbenzoylated derivatives 12 and 14, to hydrogenolytic conditions (Scheme 5B). Accordingly, treatment glycosides 12 and 14 with $\mathrm{H}_{2}$ [(35 psi), $7 \mathrm{~h}, \mathrm{Pd} / \mathrm{C}$, $\mathrm{MeOH} / \mathrm{CH}_{2} \mathrm{Cl}_{2}$ ], left the substrates unchanged, proving the stability of the benzylic BODIPY bond (Scheme $5 \mathrm{~B}$ ).

Based on these preliminary results, the hydrogenation of tri-Obenzyl-mannopyranoside 28, and tetrabenzyl mannopyranoside 34 took place uneventfully leading to triol 33 and tetraol $\alpha, \beta-13$, respectively, in excellent yields (Scheme 6A, 6B). Likewise, hydrogenation of tri-O-benzyl mannopyranoside $\mathbf{3 5}$ gave access to triol $\mathbf{3 6}$ in almost quantitative yield (Scheme 6C). Finally, to gain further knowledge on the behavior of "non-substituted" BODIPY 1 towards hydrogenation, a green fluorescent solution of mannopyranosyl BODIPY 3 was treated with $\mathrm{H}_{2}$ [(balloon), $\mathrm{Pd} / \mathrm{C}$, $\mathrm{MeOH} / \mathrm{CH}_{2} \mathrm{Cl}_{2}$ ]. After $40 \mathrm{~min}$, and in line with our previous observation (Scheme 5A), the fluorescence as well as the green color of the solution had completely disappeared. Then, acetylation of the ensuing crude reaction mixture led to the isolation of a non-fluorescent glycoside, for which we tentatively propose the structure 37 , based on its NMR and mass spectra (Scheme 6D).
From these studies, it appeared that benzyl ethers in the saccharide portion of these BODIPY glycosides could be removed chemoselectively leaving the (benzyl)BODIPY aglycon intact (e.g., Scheme 6A and Scheme 6B).

From these studies, it also seemed that the benzyl BODIPY bond between the BODIPY and the carbohydrate is more resistant to hydrogenolysis than the "standard" benzyl protecting groups, probably owing to the steric hindrance of its "ortho-BODIPY" substituent. Finally, alkylation around the BODIPY core in these derivatives played an important role in their stability towards hydrogenation, especially when compared to that of non-alkylated BODIPY 1.

Accordingly, benzyl ethers could beused as protecting groups in combination with our BODIPY derivatives, the former being able to be chemoselectively removed without tampering with the BODIPY aglycon.

From the collection of results mentioned above, it became clear that some BODIPY derivatives could tolerate, without decomposition, the protection and deprotection events commonly employed in oligosaccharide synthesis.

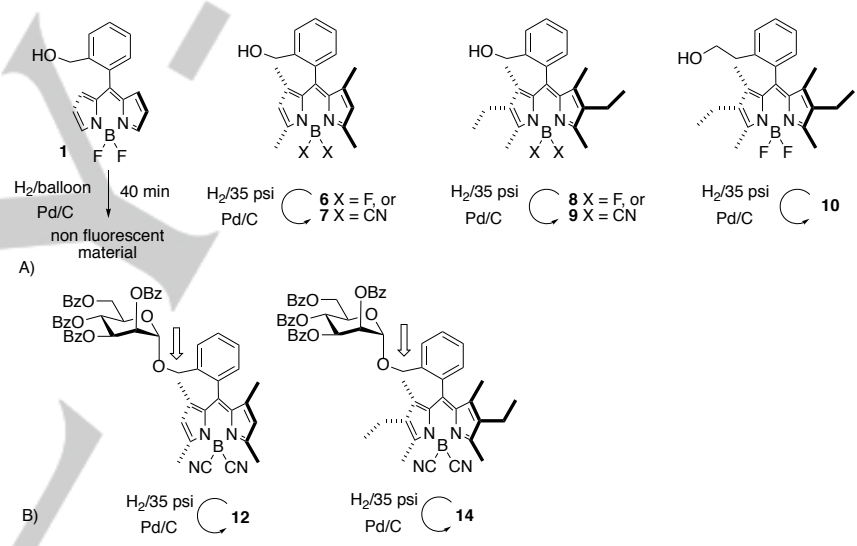

Scheme 5. Hydrogenolysis studies on BODIPYs 1, 6, 7, 8 and 10 and BODIPY glycosides 12 and 14.

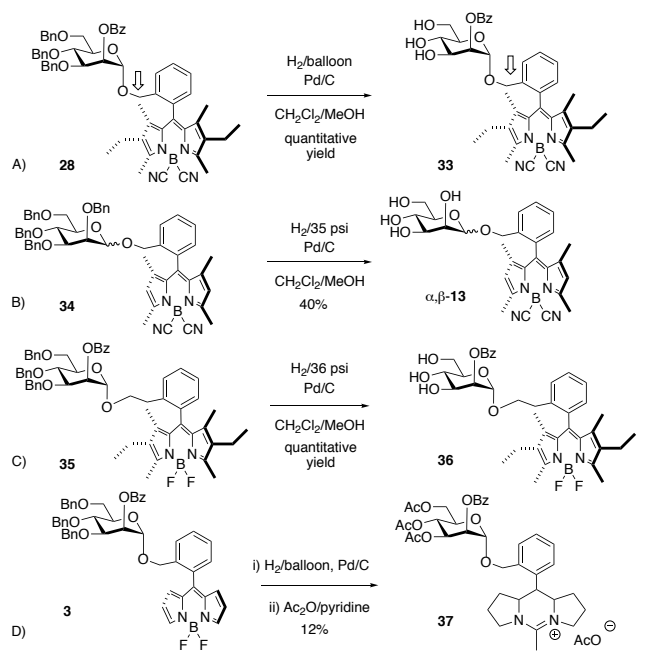

Scheme 6. Hydrogenolysis of BODIPY-glycosides 28, 34, 35 and 3. 


\section{Synthesis of BODIPY trisaccharides}

As proof of concept, and in order to illustrate the potential of BODIPY aglycons on the synthesis of oligosaccharides, we embarked on the synthesis of one linear and one branched BODIPY-labeled mannose trisaccharides 38 and $\mathbf{3 9}$, respectively (Scheme 7A,B). Thus, unprotected mannopyranoside 15 (Scheme 3B) was glycosylated with perbenzoylated thioglycoside 18 to give disaccharide 40 , which was then regioselectively glycosylated at $\mathrm{O}-3$ with NPOE $41,{ }^{[49]}$ to yield branched trimannan 38a. Saponification of the latter $(\mathrm{NaOMe} / \mathrm{MeOH})$ yielded unprotected trisaccharide $\mathbf{3 8 b}$ (Scheme 7A). On the other hand, the route to linear trimannan derivative 39, started from 6-hydroxy mannopyranoside 21 (Scheme 3D), which upon glycosylation with thioglycoside donor 19 , mediated by $\mathrm{NIS} / \mathrm{Yb}(\mathrm{OTf})_{3}$, produced disaccharide 42a. De-O-silylation of the latter $(\mathrm{HCl} / \mathrm{MeOH}, \mathrm{MW}$ irradiation) yielded disaccharide $\mathbf{4 2 b}$, in fairly good yield. Finally, glycosylation of disaccharide $\mathbf{4 2 b}$ with phenyl thioglycoside 18 generated trisaccharide 39a, which upon de-O-benzoylation yielded linear BODIPY-labeled trimannan 39b (Scheme 7B).

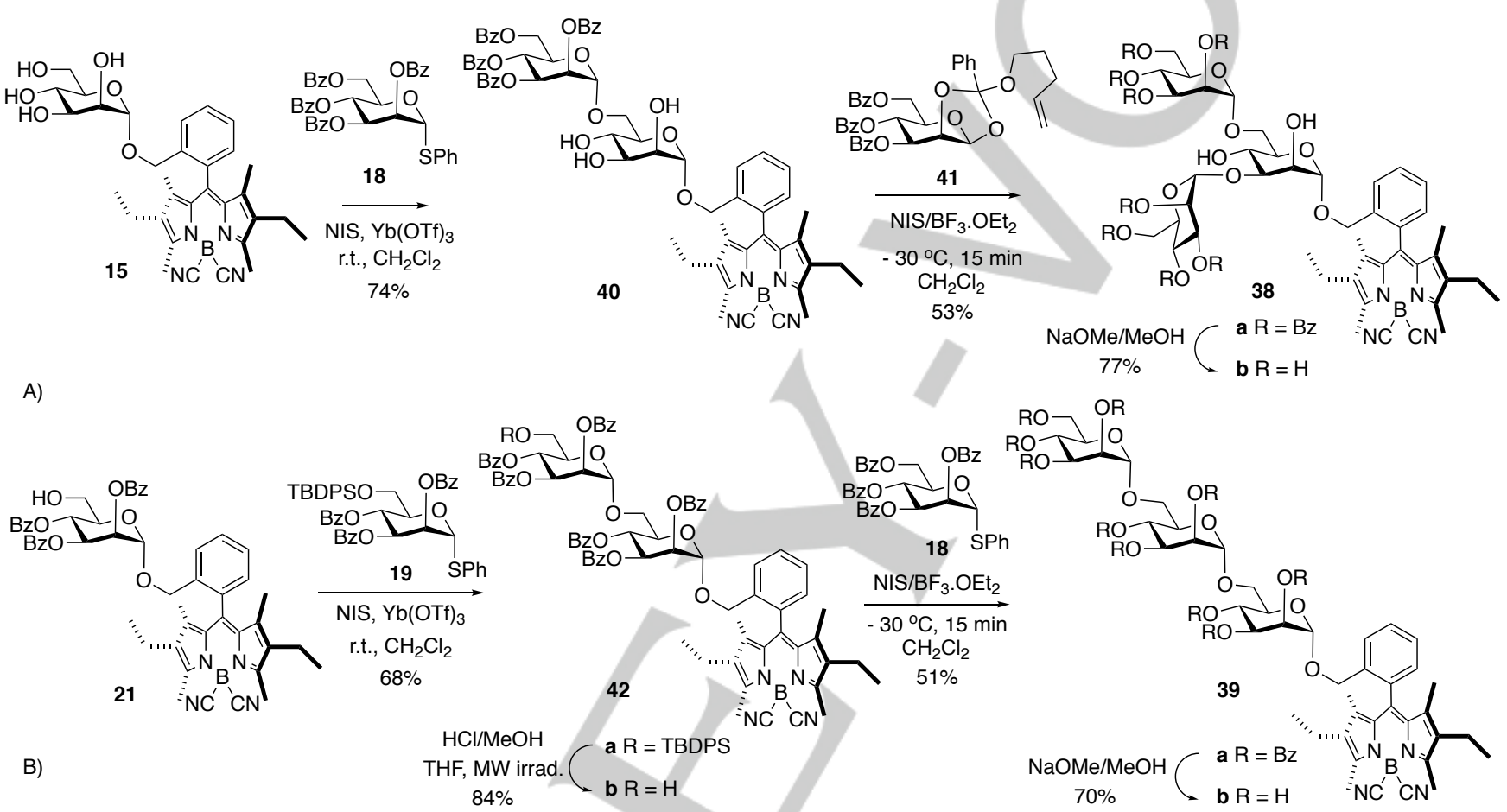

Scheme 7. A) Synthesis of branched trisaccharides $\mathbf{3 8}$, and B) synthesis of linear trisaccharides $\mathbf{3 9}$, containing 4,4'dicyano-BODIPY $\mathbf{9}$, as the aglycon.

\section{Photophysical studies}

To impel the advanced applications of the new glycoprobes we have analyzed the photonic behavior under low (photophysical properties) and high (laser properties) irradiation regimes of some representative BODIPY-labeled saccharides. The orthoglycosylation of the chromophoric C-8-benzyl group led to a rigid and compact molecular structure, owing to a higher steric hindrance imposed by the bulky saccharides (up to three units in 38a and 38b). In fact, the structural arrangement of the C-8benzyl residue was nearly orthogonal (twisting dihedral angle computed in the ground state of $85-90^{\circ}$ in analogues 15 and $\mathbf{1 7}$, Figure 2) reducing the internal conversion pathways associated to its free motion. Such geometrical disposition explained the low impact of the grafted functionalization (number of saccharide units, sugar protecting groups, and chain-length between the saccharide and the 8-aryl unit) on the photophysical signatures and the recorded high fluorescence efficiencies (Table 3 ). The replacement at the boron bridge of fluorine atoms ( $F$-BODIPYs) by cyano groups ( $C N$-BODIPYs) had low impact on the spectral properties of the BODIPYs (Figure 3), but induced an increase of the emission efficiency (see for example 17 versus 15 in Table 3), reaching values higher than $80 \%$, and approaching the value reported for the parent 1,3,5,7,8-pentamethyl-2,6diethylpyrromethene-difluoroborate (pyrromethene PM567) dye (Table 3). ${ }^{[50]}$ Such enhancement, upon chemical modification at the boron bridge with electron withdrawing groups, agreed with previously reported results with similar functionalization at the boron center. ${ }^{[32 b]}$

It is worth mentioning that the glycoprobes based on fully unprotected saccharides, such as 17 and 15 (with a monosaccharide) and $\mathbf{3 8 b}$ (with a trisaccharide) displayed high water solubility. If fact, these derivatives, and particularly those based on 4,4'-dicyano BODIPYs, displayed a remarkable fluorescence efficiency in water, reaching quantum yield values up to $82 \%$ (Table 3). Nevertheless, they showed a slight trend 
toward molecular aggregation by increasing the dye concentration in water. For example, $\mathbf{3 8} \mathbf{b}$ that became soluble in water at concentrations as high as $2 \mathrm{mM}$, tended to aggregate at concentrations higher than $0.1 \mathrm{mM}$, as it was revealed by the increased absorbance observed at the short-wavelength vibronic shoulder (Figure $\mathrm{S} 1$ in ESI). Such change in the absorption spectrum profiles can be regarded as a fingerprint of nonemissive $\mathrm{H}$-aggregates, which decreased the fluorescence response and impaired an effective laser action. However, it is worth mentioning that a water-soluble and highly fluorescent BODIPY at concentrations up to $0.1 \mathrm{mM}$ fulfilled the requirements normally demanded in biological microscopy studies. By corollary, from a photophysical standpoind, the ensuing BODIPY-labeled saccharides could be used as stable and fluorescent watersoluble chromophores addressing one of the current challenges in molecular imaging.
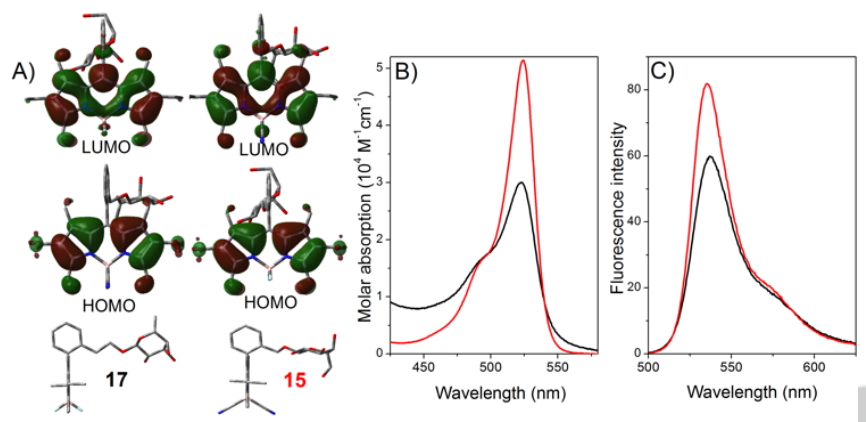

Figure 2. Computed frontier molecular orbitals (A, b3lyp/6-311 $\mathrm{g}^{*}$ ) involved in the recorded absorption (B), and fluorescence (C, scaled by their efficiency) transitions in water for the BODIPY-labeled monosaccharide 17 (in black) and its analogue 15 (in red), where the 4,4'-fluorine atoms are replaced by cyano groups. The ground state optimized geometries in side-view $(\mathrm{A})$ are also shown to highlight the orthogonal arrangement of the 8-aryl moiety linked to the BODIPY scaffold.

\section{Lasing properties}

According to their absorption properties, the lasing properties of the new dyes were studied under pumping at $532 \mathrm{~nm}$. Under our experimental conditions (transversal excitation and strong focusing of the incoming pump radiation) the concentration of the dyes should be in the millimolar range, to ensure total absorption of the pump radiation within the first millimeter at most of the solution, in order to obtain an emitted beam with near-circular cross-section and optimize the lasing efficiency (ratio between the energy of the dye laser output and the pump energy incident on the sample surface). To determine the dye concentration that optimizes the laser emission of the new dyes, first the dependence of their laser emission on the corresponding dye concentrations was analyzed in methanol by varying the concentration from 0.1 to $2 \mathrm{mM}$, while keeping all the other experimental parameters constant. In all cases the dyes followed the typical behavior, with the lasing efficiency first increasing with dye concentration until a maximum value is reached. Increasing the dye concentration beyond this point results in a decrease of the lasing efficiency that can be related to reabsorption/reemission processes, which become increasingly important as the dye concentration rises. The optimum value of the dye concentration so determined was then used to analyze the effect of the molecular structure solvent on the laser properties of the different derivatives. The lasing data recorded under these experimental conditions are collected in Table 3.

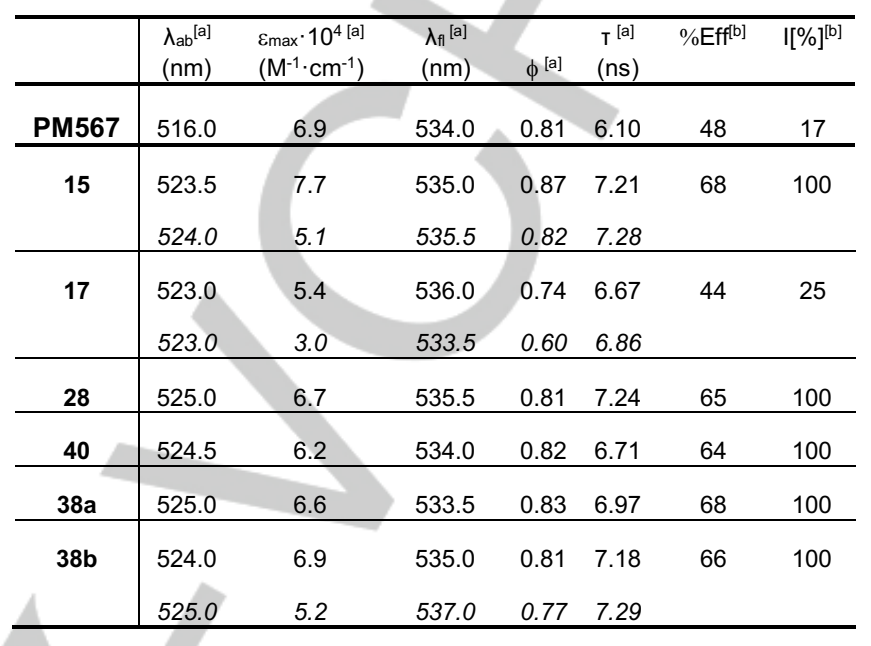

Table 3. Photophysical[a] and lase ${ }^{[\mathrm{b}]}$ properties of the herein synthesized glycoprobes in a common solvent (methanol). The corresponding data for the water-soluble compounds (in $\mathrm{H}_{2} \mathrm{O}$ ) are also included (in italics). Additional photophysical data in other solvents are collected in Table S1 in ESI.

[a] Dye concentration: $2 \mu \mathrm{M}$. Absorption $\left(\lambda_{\mathrm{ab}}\right)$ and fluorescence $\left(\lambda_{\mathrm{f}}\right)$ wavelength, molar absorption at the maximum ( $\left.\varepsilon_{\max }\right)$, fluorescence quantum yield $(\phi)$ and lifetime $(\tau)$. [b] Dye concentration $0.8 \mathrm{mM}$. Laser efficiency $(E f f(\%))$ and photostability $(\mathrm{I}(\%))$ : intensity of the laser output after 100000 pump pulses with respect to its initial intensity $\mathrm{I}_{0} ; \mathrm{I}(\%)=\left(\mathrm{I} / \mathrm{I}_{0}\right) \times 100$, at $10 \mathrm{~Hz}$ repetition rate.

All the new dyes exhibited laser action peaked at ca. $570 \mathrm{~nm}$, with a pump threshold energy of $0.8 \mathrm{~mJ}$, a beam divergence of 0.5 mrad, and a pulse duration of $8 \mathrm{~ns}$ full-width at half maximum (FWHM). The observed lasing efficiencies correlated well with their photophysical properties; a) the higher the fluorescence quantum yield the higher became the lasing efficiency; b) the replacement at the boron bridge of the fluorine atoms by cyano groups enhanced significantly the lasing efficiency, i.e. from a $48 \%$ recorded for 17 to an impressive $68 \%$ recorded for its similar cyano derivative 15 ; and $c$ ) the lasing efficiency of the glycoprobes built on F-BODIPY as well as on CN-BODIPY scaffold became independent on the structure of the saccharide inserted in the final dye, (i.e. protected and unprotected mono-, di-, and tri-saccharides led to a lasing efficiency ca. $48 \%$ for $F$ BODIPYs and a $68 \%$ for the corresponding C-BODIPYs).

An important parameter for any practical applications of these glycoprobes is their lasing photostability under hard radiation conditions and long operation times. A reasonable evaluation of the photostability of these dyes can be obtained by irradiating a small amount of solution with exactly the same pumping energy and geometry as used in the laser experiments, and monitoring the evaluation of the laser-induced fluorescence intensity with respect to the number of pump pulses (see Experimental Section). In Table 3 are collected data on the decrease of the laser-induced fluorescence intensity under transversal excitation at $532 \mathrm{~nm}$, with 
$5 \mathrm{~mJ} /$ pulse and $10 \mathrm{~Hz}$ repetition rate after 100000 pump pulses, for the new glycoprobes herein synthesized. Once again, the lasing photostability of the new BODIPY-saccharides matched their photophysical properties since the lower the non-radiative rate constant, the higher became the resistance to pumping showed by the new dyes regardless of the saccharide inserted in its molecular structure. In this way, the glycoprobes derived from the $C N$-BODIPY skeleton behaved as highly efficient and photostable dyes since its laser emission remained at its initial level after 100000 pump pulses enhancing that recorded with the corresponding F-BODIPY saccharides which lasing emission dropped more than $80 \%$ in the same pumping period.

\section{Conclusions}

In order to validate the potential of BODIPY-dyes as aglycons in synthetic sequences leading to saccharides, we have performed a comprehensive study of the compatibility of some BODIPY derivatives with the reaction conditions normally employed in these protocols, namely: i) glycosylation and ii) protecting-group manipulations. Regarding the glycosylation phase, we have evaluated the endurance of BODIPY derivatives in glycosylations with glycosyl tricholoracetimidates, thioglycosides, $n$-pentenyl orthoesters (NPOEs), 1,2-methyl orthoesters (MeOEs) or glycosyl bromides, as glycosyl donors. From the standpoint of protectinggroup manipulations, we have identified reaction conditions, which do not tamper with the BODIPY-core and allow the removal of silyl and benzoyl substituents, as representative of "temporary" protecting groups, and of benzyl substituents as protecting groups regarded as "permanent". ${ }^{[36]}$ In general, and in keeping with literature precedents, ${ }^{[33]}$ we have found that $\mathrm{B}(\mathrm{CN})_{2}$-BODIPYs are more resistant to acidic conditions than the corresponding $\mathrm{BF}_{2-}$ derivatives. The latter, however, are relatively more stable than the former under basic conditions. Also noteworthy, we have observed that the substitution pattern on the dipyrromethene-core also plays a significant role on the stability of the dye. Thus, 1,3,5,7-tetramethyl-2,6-diethyl BODIPY derivatives, i.e. 8, 9, proved to be more stable than their corresponding 2,6-des-ethyl analogues, i.e. 6, 7, under either acidic or basic conditions.

Accordingly, it has become apparent from these studies that BODIPY derivatives $\mathbf{8}$ or $\mathbf{9}$, could be successfully employed as aglycons in synthetic oligosaccharide synthesis. As such, they could play a dual role, as glycosyl tags by facilitating the visualization and identification of reaction products, and as fluorescent labels in the target oligosaccharides.

Appealingly, from a synthetic standpoint, access to these BODIPYs could be carried out efficiently in gram-scale operations. Thus, BODIPY 8 is readily obtained by a one-step reaction from 2,4-dimethyl-3-ethyl pyrrole and phthalide, ${ }^{[21]}$ and $\mathrm{B}(\mathrm{CN})_{2-}$ BODIPY 9 is then easily available from $\mathrm{BF}_{2}$-BODIPY 7 by reaction with $\mathrm{TMSCN}$ mediated by $\mathrm{BF}_{3} \cdot \mathrm{OEt}_{2}$. ${ }^{[32]}$

From the photophysical perspective, $\mathrm{B}(\mathrm{CN})_{2}$-BODIPYs displayed better photophysical properties than the corresponding $\mathrm{BF}_{2-}$ derivatives, possibly making $\mathrm{B}(\mathrm{CN})_{2}$-BODIPY 9 the aglycon of choice in BODIPY-assisted fluorescent-saccharides synthesis. In addition, we have found that the carbohydrate subunits have a beneficial effect on the, already good, photophysical features of these BODIPY-dyes.

In summary, the incorporation of a BODIPY-tag at the reducing end of the target saccharide could prove particularly useful in glycosylations when an excess of non-fluorescent glycosyl donors will be required, since it allows the easy visualization of the fluorescent final product and the unreacted glycosyl acceptor.

\section{Experimental Section}

Representative example: synthesis of fluorescently-labeled branched trisaccharide $36 \mathrm{~b}$, using $\left[\mathrm{B}(\mathrm{CN})_{2}\right] \mathrm{BODIPY} 9$ as the aglycon.

Synthesis of $\mathrm{B}(\mathrm{CN})_{2}$-BODIPY 9 from $\mathrm{BF}_{2}$-BODIPY 8. A solution of $\mathrm{BF}_{2}$ BODIPY $8^{[21]}(1.3 \mathrm{~g}, 3.17 \mathrm{mmol})$ in dry $\mathrm{CH}_{2} \mathrm{Cl}_{2}(20 \mathrm{~mL})$ was cooled to $0{ }^{\circ} \mathrm{C}$ and treated with $\mathrm{BF}_{3} \cdot \mathrm{OEt}_{2}(78 \mu \mathrm{L}, 0.63 \mathrm{mmol})$. The mixture was stirred at r.t. for $5-10 \mathrm{~min}$, then TMSCN $(1.97 \mathrm{~mL}, 15.8 \mathrm{mmol})$ was added and the reaction mixture kept under these conditions for $120 \mathrm{~min}$. The reaction was neutralized with saturated aqueous $\mathrm{NaHCO}_{3}$ solution, diluted with $\mathrm{CH}_{2} \mathrm{Cl}_{2}$ $(\mathrm{x} \mathrm{mL})$ and washed with water $(2 \mathrm{x} \times \mathrm{mL})$. The organic phase was dried over $\mathrm{MgSO}_{4}$, concentrated and purified on a silica gel column (hexaneethyl acetate; 9:1). 9 (1.17 g mg, 87\%); ${ }^{1} \mathrm{H} \mathrm{NMR}\left(400 \mathrm{MHz}, \mathrm{CDCl}_{3}\right) \delta 7.70$ $(\mathrm{d}, J=7.7 \mathrm{~Hz}, 1 \mathrm{H}), 7.55(\mathrm{~d}, J=7.6 \mathrm{~Hz}, 1 \mathrm{H}), 7.44(\mathrm{t}, J=7.5 \mathrm{~Hz}, 1 \mathrm{H}), 7.18$ (d, $J=7.7 \mathrm{~Hz}, 1 \mathrm{H}$ ), $4.56(\mathrm{~s}, 2 \mathrm{H}), 2.69(\mathrm{~s}, 6 \mathrm{H}), 2.34$ (q, $J=7.6 \mathrm{~Hz}, 4 \mathrm{H}), 1.31$ (s, 6H), $1.00(\mathrm{t}, J=7.6 \mathrm{~Hz}, 6 \mathrm{H}) ;{ }^{13} \mathrm{C} \mathrm{NMR}\left(100 \mathrm{MHz}, \mathrm{CDCl}_{3}\right) \delta$ 154.4, 139.7 , 139.2, 138.3, 134.5 (broad C), 132.6, 130.0, 128.8 (broad C), 128.6, 128.1, 62.3, 17.3, 14.6, $13.5,11.5 .{ }^{19} \mathrm{~F} \mathrm{NMR}\left(376 \mathrm{MHz}, \mathrm{CDCl}_{3}\right)$ : no peaks; ${ }^{11} \mathrm{~B}$ NMR ( $\left.128 \mathrm{MHz}, \mathrm{CDCl}_{3}\right) \delta-16.25$; HRMS (ESI-TOF): calc for $\mathrm{C}_{26} \mathrm{H}_{30} \mathrm{BN} \mathrm{BN}_{4} \mathrm{O}$ : $[\mathrm{M}+\mathrm{H}]^{+} 425.25118$; found: 425.25088 .

Mannopyranosyl BODIPY 14. To a solution of BODIPY-acceptor 9 (424 $\mathrm{mg}, 1 \mathrm{mmol})$ and TCA $11(1 \mathrm{~g}, 1.36 \mathrm{mmol})$ in anhydrous $\mathrm{CH}_{2} \mathrm{Cl}_{2}(15 \mathrm{~mL})$ was added $4 \AA$ molecular sieves $(100 \% \mathrm{w} / \mathrm{w})$. The mixture was stirred at it for about $15 \mathrm{~min}$ under an $\mathrm{Ar}$ atmosphere, then cooled down to $-78^{\circ} \mathrm{C}$. $\mathrm{NEW} \mathrm{BF} \mathrm{OEt}_{2}(84 \mu \mathrm{L}, 0.68 \mathrm{mmol})$ was then added and the reaction mixture kept at this temperature. The mixture was stirred under these conditions for $30 \mathrm{~min}$, and then neutralized by addition of $\mathrm{Et}_{3} \mathrm{~N}(1 \mathrm{~mL})$. The mixture was evaporated and chromatographed over silica gel flash column (hexane-ethyl acetate, 8:2) to give compound 14 (661 mg, 66\%). Red filmlike solid product, $[\alpha]_{\mathrm{D}^{21}}=+15.1$ (c 0.4 in $\left.\mathrm{CHCl}_{3}\right) ;{ }^{1} \mathrm{H}$ NMR $(500 \mathrm{MHz}$, $\left.\mathrm{CDCl}_{3}\right) \delta 8.01-7.16(\mathrm{~m}, 24 \mathrm{H}), 6.01(\mathrm{t}, J=10.1 \mathrm{~Hz}, 1 \mathrm{H}), 5.63(\mathrm{dd}, J=10.2$, $3.3 \mathrm{~Hz}, 1 \mathrm{H}), 5.28(\mathrm{dd}, J=3.3,1.8 \mathrm{~Hz}, 1 \mathrm{H}), 4.91(\mathrm{~d}, J=1.8 \mathrm{~Hz}, 1 \mathrm{H}), 4.64$ (d, $J=11.5 \mathrm{~Hz}, 1 \mathrm{H}), 4.57$ (dd, $J=12.3,2.7 \mathrm{~Hz}, 1 \mathrm{H}), 4.40(\mathrm{~d}, J=11.5 \mathrm{~Hz}$, $1 \mathrm{H}), 4.34(\mathrm{dd}, J=12.3,3.4 \mathrm{~Hz}, 1 \mathrm{H}$ ), $4.19(\mathrm{dt}, J=10.1,3.1 \mathrm{~Hz}, 1 \mathrm{H}), 2.60$ $(\mathrm{s}, 6 \mathrm{H}), 2.38-2.19(\mathrm{~m}, 4 \mathrm{H}), 1.36(\mathrm{~s}, 3 \mathrm{H}), 1.25(\mathrm{~s}, 3 \mathrm{H}), 0.91(\mathrm{t}, J=7.5 \mathrm{~Hz}$, $3 \mathrm{H}), 0.90(\mathrm{t}, J=7.5 \mathrm{~Hz}, 3 \mathrm{H}) \cdot{ }^{13} \mathrm{C} \mathrm{NMR}\left(126 \mathrm{MHz}, \mathrm{CDCl}_{3}\right) \delta 166.2,165.5$, 165.1, 156.1, 153.9, 140.4, 139.0, 138.4, 135.3, 134.7, 134.4, 134.3, 133.5, 133.4, 133.3, 133.1, 130.3, 130.1, 130.0, 129.9, 129.8, 129.7, 129.5, 129.2, 128.8, 128.6, 128.5, 128.4. ${ }^{11} \mathrm{~B}$ NMR $\left(128 \mathrm{MHz}, \mathrm{CDCl}_{3}\right) \delta-16.16 .{ }^{19} \mathrm{~F}$ NMR ( $376 \mathrm{MHz}, \mathrm{CDCl}_{3}$ ): no peaks. HRMS (ESI-TOF): calcd for $\mathrm{C}_{60} \mathrm{H}_{59} \mathrm{BN}_{5} \mathrm{O}_{10}$ : $\left[\mathrm{M}+\mathrm{NH}_{4}\right]^{+}$1020.43594, found: 1020.43754 . calcd for $\mathrm{C}_{60} \mathrm{H}_{55} \mathrm{BN}_{4} \mathrm{NaO}_{10}$ : $[\mathrm{M}+\mathrm{Na}]^{+}$1025.39133, found: 1025.39126 .

Mannopyranosyl-tetraol BODIPY 15. A solution of BODIPY mannopyranoside $14(572 \mathrm{mg}, 0.57 \mathrm{mmol})$ in $\mathrm{MeOH}(10 \mathrm{~mL})$ was treated with $\mathrm{NaOMe}(184 \mathrm{mg}, 3.42 \mathrm{mmol})$. After stirring at room temperature for 3 $\mathrm{h}$, the solution was neutralized with ion-exchange resin $\left(\mathrm{H}^{+}\right)$, then filtered and concentrated. The residue was purified by column chromatography on silica gel ( $\left.\mathrm{MeOH}: \mathrm{CH}_{2} \mathrm{Cl}_{2} ; 9: 1\right)$ to provide tetraol $15(228 \mathrm{mg}, 70 \%)$ as a red solid. m. p. $140.1^{\circ} \mathrm{C}$ (decomposition); $[\alpha]^{21}=+179.4$ (c 0.07 in $\mathrm{MeOH}$ ); ${ }^{1} \mathrm{H} \mathrm{NMR}\left(500 \mathrm{MHz}, \mathrm{CDCl}_{3}\right) \delta 7.61-7.44(\mathrm{~m}, 3 \mathrm{H}), 7.21(\mathrm{~d}, J=7.2 \mathrm{~Hz}, 1 \mathrm{H})$, 
$4.67(\mathrm{~s}, 1 \mathrm{H}), 4.50(\mathrm{~d}, J=11.0 \mathrm{~Hz}, 1 \mathrm{H}), 4.22(\mathrm{~d}, J=11.4 \mathrm{~Hz}, 1 \mathrm{H}), 3.80-$ $3.55(\mathrm{~m}, 2 \mathrm{H}), 3.53-3.34(\mathrm{~m}, 3 \mathrm{H}), 3.13-2.99(\mathrm{~m}, 1 \mathrm{H}), 2.66(\mathrm{~m}, 6 \mathrm{H}), 2.44$ $-2.25(\mathrm{~m}, 4 \mathrm{H}), 1.27(\mathrm{~s}, 6 \mathrm{H}), 1.00(\mathrm{q}, J=7.5 \mathrm{~Hz}, 6 \mathrm{H}) .{ }^{13} \mathrm{C} \mathrm{NMR}(126 \mathrm{MHz}$, $\left.\mathrm{CDCl}_{3}\right) \delta 154.5,154.3,140.0,139.8,139.1,134.8,134.7,134.5,133.8$, $130.0,129.9,129.3,129.0,128.7,128.3,100.2,72.4,71.5,70.6,67.3$, $65.8,60.6,17.3,14.6,14.5,13.5,11.6,11.5 .{ }^{11} \mathrm{~B} \mathrm{NMR}\left(128 \mathrm{MHz}, \mathrm{CDCl}_{3}\right)$ $\delta$-16.25. HRMS (ESI-TOF): calcd for $\mathrm{C}_{32} \mathrm{H}_{43} \mathrm{BN}_{5} \mathrm{O}_{6}:\left[\mathrm{M}+\mathrm{NH}_{4}\right]^{+} 604.33066$ found: 604.33040 . calcd for $\mathrm{C}_{32} \mathrm{H}_{39} \mathrm{~B} \mathrm{~N} \mathrm{NaOO}_{6}:[\mathrm{M}+\mathrm{Na}]^{+} 609.28605$, found: 609.28555 .

BODIPY-disaccharide 40. To a stirred solution of tetraol $15(50 \mathrm{mg}, 0.087$ $\mathrm{mmol})$, and thioglycoside donor $18(139 \mathrm{mg}, 0.22 \mathrm{mmol})$ and $\mathrm{N}$ iodosuccinimide (NIS) $\left(49 \mathrm{mg}, 0.22 \mathrm{mmol}\right.$ ) in $\mathrm{CH}_{2} \mathrm{Cl}_{2}(8 \mathrm{~mL}), \mathrm{Yb}$ (OTf) 3 (136 $\mathrm{mg}, 0.22 \mathrm{mmol}$ ) was added at room temperature. The reaction mixture was stirred for $15 \mathrm{~min}$ and then partitioned between aqueous sodium thiosulfate/ $\mathrm{NaHCO}_{3}$ and $\mathrm{CH}_{2} \mathrm{Cl}_{2}$. After washing with water and brine, the combined organic extracts were dried over anhydrous $\mathrm{Na}_{2} \mathrm{SO}_{4}$, and evaporated. The residue was chromatographed over silica gel flash column (hexane-ethyl acetate, 6:4) to give dissacharide $\mathbf{4 0}(75 \mathrm{mg}, \mathbf{7 4 \%})$ as a red film-like solid . $[\alpha]_{\mathrm{D}}{ }^{21}=+392.1\left(c 0.2 \mathrm{in} \mathrm{CHCl}_{3}\right) .{ }^{1} \mathrm{H} \mathrm{NMR}(500 \mathrm{MHz}$, $\left.\mathrm{CDCl}_{3}\right) \delta 8.21-7.69(\mathrm{~m}, 8 \mathrm{H}), 7.67-7.21(\mathrm{~m}, 16 \mathrm{H}), 6.11(\mathrm{t}, J=10.2 \mathrm{~Hz}$ $1 \mathrm{H}), 5.94(\mathrm{dd}, J=10.2,3.3 \mathrm{~Hz}, 1 \mathrm{H}), 5.69(\mathrm{dd}, J=3.3,1.8 \mathrm{~Hz}, 1 \mathrm{H}), 5.24(\mathrm{~d}$, $J=1.8 \mathrm{~Hz}, 1 \mathrm{H}), 4.72-4.64(\mathrm{~m}, 3 \mathrm{H}), 4.58-4.52(\mathrm{~m}, 1 \mathrm{H}), 4.47(\mathrm{dd}, J=$ $12.2,4.1 \mathrm{~Hz}, 1 \mathrm{H}), 4.35(\mathrm{~d}, J=11.3 \mathrm{~Hz}, 1 \mathrm{H}), 3.97(\mathrm{dd}, J=11.4,5.5 \mathrm{~Hz}, 1 \mathrm{H})$, $3.89(\mathrm{dd}, J=11.4,1.9 \mathrm{~Hz}, 1 \mathrm{H}), 3.70(\mathrm{td}, J=9.6,2.7 \mathrm{~Hz}, 1 \mathrm{H}), 3.59-3.52$ $(\mathrm{m}, 1 \mathrm{H}), 3.31$ (td, $J=9.1,3.5 \mathrm{~Hz}, 1 \mathrm{H}), 3.28-3.21(\mathrm{~m}, 1 \mathrm{H}), 2.70(\mathrm{~s}, 3 \mathrm{H})$, $2.68(\mathrm{~s}, 3 \mathrm{H}), 2.39-2.31(\mathrm{~m}, 4 \mathrm{H}), 1.35(\mathrm{~s}, 3 \mathrm{H}), 1.30(\mathrm{~s}, 3 \mathrm{H}), 1.04-0.97$ $(\mathrm{m}, 6 \mathrm{H}) .{ }^{13} \mathrm{C}$ NMR $\left(126 \mathrm{MHz}, \mathrm{CDCl}_{3}\right) \delta 166.3,165.7,165.6,154.2,154.1$, 140.6, 140.1, 139.9, 134.7, 134.6, 133.6, 133.5, 133.3, 133.1, 131.0, 130.1, 130.0, 129.9, 129.6, 129.4, 129.2, 128.7, 128.6, 128.5, 128.4, 100.6, 97.6, $71.9,71.5,70.9,70.1,69.9,69.2,69.0,68.1,67.1,66.9,63.0,17.4,17.3$, 14.6, 13.6, 11.9, 11.5. HRMS (ESI-TOF): calcd for $\mathrm{C}_{66} \mathrm{H}_{69} \mathrm{BN}_{5} \mathrm{O}_{15}$ : $\left[\mathrm{M}+\mathrm{NH}_{4}\right]^{+}$1182.4885 found: 1182.49303. calcd for $\mathrm{C}_{66} \mathrm{H}_{65} \mathrm{BN}_{4} \mathrm{NaO}_{15}$ : $[\mathrm{M}+\mathrm{Na}]^{+} 1187.44424$, found: 1187.44934 .

BODIPY-trisaccharide 38a. To a stirred solution of BODIPY-disaccharide $40(41 \mathrm{mg}, 0.035 \mathrm{mmol})$, NPOE donor $41(70 \mathrm{mg}, 0.105 \mathrm{mmol})$ and $\mathrm{N}$ iodosuccinimide (23 mg, $0.105 \mathrm{mmol}$ ) in $\mathrm{CH}_{2} \mathrm{Cl}_{2}(8 \mathrm{~mL}), \mathrm{BF}_{3} \mathrm{OEt}_{2}(5 \mu \mathrm{L}$, $0.022 \mathrm{mmol}$ ) was added at $-30^{\circ} \mathrm{C}$. The reaction mixture was stirred for 15 min and then partitioned between aqueous sodium thiosulfate/ $\mathrm{NaHCO}_{3}$ and $\mathrm{CH}_{2} \mathrm{Cl}_{2}$. After washing with water and brine, the combined organic extracts were dried over anhydrous $\mathrm{Na}_{2} \mathrm{SO}_{4}$, and evaporated. The residue was chromatographed over silica gel flash column (hexane-ethyl acetate, 6:4) to give compound $\mathbf{3 8 a}$ as a non crystalline red film-like solid product $(76 \mathrm{mg}, 53 \%) .[\alpha]^{21}=-125.9\left(c 0.9 \mathrm{in} \mathrm{CHCl}_{3}\right) .{ }^{1} \mathrm{H} \mathrm{NMR}\left(500 \mathrm{MHz}, \mathrm{CDCl}_{3}\right)$ $\delta 8.19-7.76(\mathrm{~m}, 16 \mathrm{H}), 7.67-7.17(\mathrm{~m}, 28 \mathrm{H}), 6.20(\mathrm{t}, J=10.2 \mathrm{~Hz}, 1 \mathrm{H})$, $6.14(\mathrm{t}, J=10.1 \mathrm{~Hz}, 1 \mathrm{H}), 5.98(\mathrm{dd}, J=4.5,3.2 \mathrm{~Hz}, 1 \mathrm{H}), 5.96(\mathrm{dd}, J=4.4$ $3.3 \mathrm{~Hz}, 1 \mathrm{H}), 5.78(\mathrm{dd}, J=3.2,1.9 \mathrm{~Hz}, 1 \mathrm{H}), 5.73(\mathrm{dd}, J=3.3,1.8 \mathrm{~Hz}, 1 \mathrm{H})$, $5.34(\mathrm{~d}, J=1.8 \mathrm{~Hz}, 1 \mathrm{H}), 5.10(\mathrm{~d}, J=2.0 \mathrm{~Hz}, 1 \mathrm{H}), 4.86(\mathrm{dt}, J=10.3,3.1 \mathrm{~Hz}$ $1 \mathrm{H}), 4.73(\mathrm{dd}, J=12.2,2.5 \mathrm{~Hz}, 1 \mathrm{H}), 4.67(\mathrm{~d}, J=1.7 \mathrm{~Hz}, 1 \mathrm{H}), 4.64(\mathrm{dd}, J=$ $12.3,2.6 \mathrm{~Hz}, 1 \mathrm{H}), 4.62(\mathrm{~d}, J=11.2 \mathrm{~Hz}, 1 \mathrm{H}), 4.60-4.53(\mathrm{~m}, 2 \mathrm{H}), 4.50(\mathrm{dd}$, $J=12.2,3.9 \mathrm{~Hz}, 1 \mathrm{H}), 4.25(\mathrm{~d}, J=11.1 \mathrm{~Hz}, 1 \mathrm{H}), 4.15(\mathrm{t}, J=9.7 \mathrm{~Hz}, 1 \mathrm{H})$, $4.03(\mathrm{dd}, J=11.8,4.5 \mathrm{~Hz}, 1 \mathrm{H}), 3.89(\mathrm{dd}, J=11.8,1.8 \mathrm{~Hz}, 1 \mathrm{H}), 3.81(\mathrm{~s}$, $1 \mathrm{H}$ ), 3.63 (dd, $J=9.4,3.2 \mathrm{~Hz}, 1 \mathrm{H}$ ), 3.52 (ddd, $J=9.9,4.5,1.8 \mathrm{~Hz}, 1 \mathrm{H}$ ), $2.65(\mathrm{~s}, 3 \mathrm{H}), 2.60(\mathrm{~s}, 3 \mathrm{H}), 2.35-2.23(\mathrm{~m}, 2 \mathrm{H}), 2.22-2.13(\mathrm{~m}, 2 \mathrm{H}), 1.29$ (s, 3H), $1.29(\mathrm{~s}, 3 \mathrm{H}), 1.29(\mathrm{~s}, 3 \mathrm{H}), 0.93(\mathrm{t}, J=7.6 \mathrm{~Hz}, 3 \mathrm{H}), 0.75(\mathrm{t}, J=7.6$ $\mathrm{Hz}, 3 \mathrm{H}) .{ }^{13} \mathrm{C}$ NMR $\left(126 \mathrm{MHz}, \mathrm{CDCl}_{3}\right) \delta 166.4,166.3,165.8,165.6,165.5$ $154.6,154.4,140.0,139.7,139.4,134.8,134.6,134.5,133.7,133.6$, $133.5,133.4,133.3,133.2,133.1,131.0,130.2,130.1,130.0,129.9$, $129.5,129.4,129.3,129.2,129.1,128.8,128.7,128.6,128.5,128.4$, $100.7,99.2,97.8,82.9,72.1,71.0,70.8,70.4,70.1,69.6,69.4,69.0,68.5$, $67.1,66.6,65.1,63.0,62.9,17.4,17.3,14.6,14.4,13.6,13.5,11.8$, 11.5. ${ }^{11} \mathrm{~B}$ NMR $\left(128 \mathrm{MHz}, \mathrm{CDCl}_{3}\right) \delta-16.25$. HRMS (ESI-TOF): calcd for
$\mathrm{C}_{100} \mathrm{H}_{95} \mathrm{BN}_{5} \mathrm{O}_{24}:\left[\mathrm{M}+\mathrm{NH}_{4}\right]^{+} 1760.64696$ found: 1760.64620 . calcd for $\mathrm{C}_{100} \mathrm{H}_{91} \mathrm{BN}_{4} \mathrm{NaO}_{24}:[\mathrm{M}+\mathrm{Na}]^{+}$1765.60236, found: 1765.61089 .

BODIPY-trimannan derivative $38 \mathrm{~b}$. A solution of benzoylated trisaccharide 38a (56 mg, $0.032 \mathrm{mmol})$ in $\mathrm{MeOH}-\mathrm{CH}_{2} \mathrm{Cl}_{2}(\mathrm{~V}: \mathrm{V} / 2: 1,4 \mathrm{~mL})$ was treated with $\mathrm{NaOMe}(14 \mathrm{mg}, 0.26 \mathrm{mmol})$. After stirring at room temperature for $4 \mathrm{~h}$, the solution was neutralized with ion-exchange resin $\left(\mathrm{H}^{+}\right)$, then filtered and concentrated. The residue was purified by column chromatography on silica gel (ethyl acetate: $\left.\mathrm{MeOH}: \mathrm{H}_{2} \mathrm{O} ; 10: 2: 1\right)$ to give 38b $(22 \mathrm{mg}, 77 \%)$ as a red film-like solid $[\alpha]_{\mathrm{D}}^{21}=+960.9\left(\mathrm{c} 0.3\right.$ in $\left.\mathrm{CHCl}_{3}\right)$;. ${ }^{1} \mathrm{H}$ NMR $\left(500 \mathrm{MHz}, \mathrm{CDCl}_{3}\right) \delta 7.70(\mathrm{dd}, J=7.7,1.4 \mathrm{~Hz}, 1 \mathrm{H}), 7.63(\mathrm{td}, J=$ 7.6, $1.5 \mathrm{~Hz}, 1 \mathrm{H}), 7.58$ (dt, $J=7.5,1.4 \mathrm{~Hz}, 1 \mathrm{H}), 7.33(\mathrm{dd}, J=7.5,1.4 \mathrm{~Hz}$, $1 \mathrm{H}), 4.94(\mathrm{~d}, J=1.8 \mathrm{~Hz}, 1 \mathrm{H}), 4.78(\mathrm{~d}, J=1.7 \mathrm{~Hz}, 1 \mathrm{H}), 4.71(\mathrm{~d}, J=1.7 \mathrm{~Hz}$, $1 \mathrm{H}), 4.60(\mathrm{~d}, J=10.8 \mathrm{~Hz}, 1 \mathrm{H}), 4.27(\mathrm{~d}, J=10.9 \mathrm{~Hz}, 1 \mathrm{H}), 3.94$ (dd, $J=3.4$, $1.8 \mathrm{~Hz}, 1 \mathrm{H}), 3.91(\mathrm{dd}, J=3.4,1.7 \mathrm{~Hz}, 1 \mathrm{H}), 3.83-3.74(\mathrm{~m}, 6 \mathrm{H}), 3.73-3.65$ $(\mathrm{m}, 3 \mathrm{H}), 3.64-3.57(\mathrm{~m}, 4 \mathrm{H}), 3.45-3.40(\mathrm{~m}, 2 \mathrm{H}), 3.14(\mathrm{ddd}, J=10.1,4.8$, $1.9 \mathrm{~Hz}, 1 \mathrm{H}), 2.70(\mathrm{~s}, 3 \mathrm{H}), 2.69(\mathrm{~s}, 3 \mathrm{H}), 2.54-2.37(\mathrm{~m}, 4 \mathrm{H}), 1.42(\mathrm{~s}, 3 \mathrm{H})$, $1.37(\mathrm{~s}, 3 \mathrm{H}), 1.04(\mathrm{t}, \mathrm{J}=7.5 \mathrm{~Hz}, 67 \mathrm{H}) .{ }^{13} \mathrm{C} \mathrm{NMR}\left(126 \mathrm{MHz}, \mathrm{CDCl}_{3}\right) \delta 156.2$, $155.0,142.0,141.4,141.0,136.5,136.2,136.1,136.0,135.5,132.4$, 131.2, 130.7, 130.5, 130.2, 129.7, 103.6, 101.9, 101.2, 81.2, 74.8, 74.0, 73.3, 72.6, 72.5, 72.1, 71.9, 71.0, 68.7, 68.6, 68.1, 66.5, 66.4, 62.8, 62.7, 18.2, 18.0, 14.9, 14.9, 13.8, 13.6, 12.1, 11.9. HRMS (ESI-TOF): calcd for $\mathrm{C}_{44} \mathrm{H}_{63} \mathrm{BN}_{5} \mathrm{O}_{16}: \quad\left[\mathrm{M}+\mathrm{NH}_{4}\right]^{+} 928.43650$ found: 928.43253. calcd for $\mathrm{C}_{44} \mathrm{H}_{59} \mathrm{BN}_{4} \mathrm{NaO}_{16}:[\mathrm{M}+\mathrm{Na}]^{+}$933.39190, found: 933.39046 .

Photophysical properties. Spectroscopic properties were registered in diluted solutions (around $2 \times 10^{-6} \mathrm{M}$ ), prepared by adding the corresponding solvent (spectroscopic grade) to the residue from the adequate amount of a concentrated stock solution in acetone, after vacuum evaporation of this solvent. UV-Vis absorption spectra were recorded on a Varian model CARY 4E spectrophotometer, whereas the fluorescence and excitation spectra, as well as the decay curves were registered in an Edinburgh Instruments spectrofluorimeter (model FLSP 920). Fluorescence quantum yields $(\phi)$ were obtained using as reference commercial cresyl violet $\left(\phi^{r}=\right.$ 0.54 in methanol), for the long-wavelength emission of the energy acceptor, and commercial PM546 ( $\phi^{r}=0.81$ in methanol) to account for the green, and quenched emission owing to energy transfer, of the energy donor subunit. The values were corrected by the refractive index of the solvent. Radiative decay curves were registered with the time correlated singlephoton counting technique using a multichannel plate detector with picosecond time-resolution. Fluorescence emission was monitored at the maximum emission wavelength after excitation by means of a wavelengthtunable Fianium Supercontinuum laser. The fluorescence lifetime $(\tau)$ was obtained after the deconvolution of the instrumental response signal from the recorded decay curves by means of an iterative method. The decay curve was essentially the same regardless of the excited visible absorption band. The goodness of the exponential fit was controlled by statistical parameters (chi-square and the analysis of the residuals). The radiative $\left(\mathrm{k}_{\mathrm{fl}}\right)$ and non-radiative $\left(\mathrm{k}_{\mathrm{nr}}\right)$ rate constants were calculated from the fluorescence quantum yield and lifetime; $\mathrm{kfl}=\phi / \tau$ and $\mathrm{knr}=(1-\phi) / \tau$.

Quantum mechanical calculations. Ground state geometries were optimized at the Density Functional Theory (DFT) using range-separated hybrid wB97XD method. Th vertical Franck-Condon electronic transition was predicted by the Time Dependent (TD) method and the same functional. In both cases the double valence basis set with one polarization functions $\left(6-31 \mathrm{~g}^{*}\right)$ was used owing to the large size of the computed multichromophoric molecules. The geometries were considered as energy minimum when the corresponding frequency analysis did not give any negative value. The solvent effect (cyclohexane) was considered in the conducted theoretical simulations by means of the Polarizable Continuum Model (PCM). All the calculations were performed using the Gaussian 16 software as implemented in the computational cluster "arina" of the UPVIEHU. 
Laser properties. Laser efficiency was evaluated from concentrated solutions (milimolar) of dyes in ethyl acetate contained in $1-\mathrm{cm}$ optical-path rectangular quartz cells carefully sealed to avoid solvent evaporation during experiments. The liquid solutions were transversely pumped with 8 $\mathrm{mJ}, 8 \mathrm{~ns}$ FWHM pulses from the third harmonic $(355 \mathrm{~nm})$ or the second harmonic $(532 \mathrm{~nm})$ of a Q-switched Nd:YAG laser (Lotis TII 2134) at a repetition rate of $1 \mathrm{~Hz}$. The exciting pulses were line-focused onto the cell using a combination of positive and negative cylindrical lenses $(f=15 \mathrm{~cm}$ and $f=-15 \mathrm{~cm}$, respectively) perpendicularly arranged. The plane parallel oscillation cavity ( $2 \mathrm{~cm}$ length) consisted of a $90 \%$ reflectivity aluminium mirror acting as back reflector, and the lateral face of the cell acting as output coupler ( $4 \%$ reflectivity). The pump and output energies were detected by a GenTec powermeter. The photostability of the dyes in ethyl acetate solution was evaluated by using a pumping energy and geometry exactly equal to that of the laser experiments. We used spectroscopic quartz cuvettes with $0.1 \mathrm{~cm}$ optical to allow for the minimum solution volume $\left(V_{S}=40 \mu \mathrm{L}\right)$ to be excited. The lateral faces were grounded, whereupon no laser oscillation was obtained. Information about photostabilitiy was obtained by monitoring the decrease in laser-induced fluorescence (LIF) intensity. In order to facilitate comparisons independently of the experimental conditions and sample, the photostability figure of merit was defined as the accumulated pump energy absorbed by the system ( $E_{\text {dose }}$ ), per mole of dye, before the output energy falls to a $50 \%$ its initial value. In terms of experimental parameters, this energy dose, in units of $\mathrm{GJ} \mathrm{mol}{ }^{-1}$, can be expressed as:

$$
E_{\text {dose }}^{50 \%}\left(G J \cdot m o l^{-1}\right)=\frac{E_{\text {pump }}(G J) \cdot\left(1-10^{-\varepsilon C L}\right) \cdot \sum_{\text {\#pulses }} f}{C V_{\mathrm{S}}}
$$

where $E_{\text {pump }}$ is the energy per pulse, $C$ is the molar concentration, $\varepsilon$ is the molar absorption coefficient in units of $\mathrm{M}^{-1} \mathrm{~cm}^{-1}, \mathrm{~L}$ is the depth of the cuvette expressed in $\mathrm{cm}$, Vs is the solution volume, in litres, within the cuvette, and $f$ is the ratio between the LIF intensity after \#pulses and the LIF intensity in the first pulse. To speed up the experiment the pump repetition rate was increased up to $15 \mathrm{~Hz}$. The fluorescence emission and laser spectra were monitored perpendicular to the exciting beam, collected by an optical fiber, and imaged onto a spectrometer (Acton Research corporation) and detected with a charge-coupled device (CCD) (SpectruMM:GS128B). The fluorescence emission was recorded by feeding the signal to the boxcar (Stanford Research, model 250) to be integrated before being digitized and processed by a computer. The estimated error in the energy and photostability measurements was $10 \%$.

\section{Acknowledgements}

We gratefully acknowledge the Spanish Ministerio de Economia y Competitividad for financial support (projects CTQ2015-66702R, MAT2017-83856-C3-1-P and 3-P). We also thank the Ministerio de Ciencia Innovación y Universidades (project RTI2018-094862-B-I00) and the Gobierno Vasco for financial support (project IT912-16) and for a predoctoral fellowship to $\mathrm{E}$. A.-Z. Additionally, C.P., on leave from the Universidad Nacional de Rosario (UNR), is grateful to the EVA mobility program (UNR) for partial financial support. The authors thank SGlker of UPV/EHU for technical support with the computational calculations, which were carried out in the "arina" informatic cluster. We are very grateful to Ms. Marina Rodríguez (IQOGCSIC) for skillful technical support.
Keywords: BODIPY • glycosylation • BODIPY labels • BODIPY saccharides $\cdot$ BODIPY tags

[1] a) G.-J. Boons, Tetrahedron 1996, 52, 1095-1121; b) D. P. Galonic, D. Y. Gin, Nature 2007, 446, 1000-1007; c) X. Zhu, R. R. Schmidt, Angew. Chem. 2009, 121, 1932-1967; Angew. Chem. Int. Ed. 2009, 48, 19001934; d) Handbook of Chemical Glycosylation: Advances in Stereoselectivity and Therapeutic Relevance, (Ed.: A. V. Demchenko), Wiley-VCH: Weinheim, 2008; e) Reactivity Tuning in Oligosaccharide Assembly; (Eds.: B. Fraser-Reid, J. C. Lopez), Springer-Verlag: BerlinHeidelberg, 2011, Vol. 301.

[2] a) L. D. Davis, R. T. Raines, ACS Chem. Biol. 2008, 3, 142-155; b) H. Kobayashi, M. Ogawa, R. Alford, P. L. Choyke, Y. Urano, Chem. Rev. 2010, 110, 2620-2640; c) L. D. Davis, R. T. Raines, ACS Chem. Biol. 2014, 9, 855-866.

[3] a) M. Sawa, T.-L. Hsu, T. Itoh, M. Sugiyama, S. R. Hanson, P. K. Vogt, C.-H. Wong, Proc. Natl. Acad. Sci. USA 2006, 103, 12371-12376; b) L. Krishnamoorthy, L. K. Mahal, ACS Chem. Biol. 2009, 9, 715-732; c) S. T. Laughlin, C. R. Bertozzi, Proc. Natl. Acad. Sci. USA 2009, 106, 12-17; cd H. Yan, R. S. Yalagala, F. Yan, Glycoconj. J. 2015, 32, 559-574; d) B. Thomas, K.-C. Yan, X.-L. Hu, M. Donnier-Maréchal, G.-R. Chen, X.P. He, S. Vidal, Chem. Soc. Rev. 2020, DOI: 10.1039/c8cs00118a.

[4] Y, Mechref, M. V. Novotny, Chem. Rev. 2002, 102, 321-369.

[5] a) B. Xia, Z. S. Kawar, T. Ju, R. A. Alvarez, G. P. Sachdev, R. D. Cummings, Nature Methods 2005, 2, 845-850; b) A. Lohse, R. Martins, M. R. Jørgensen, O. Hindsgaul, Angew. Chem. 2006, 118, 4273-4278; Angew. Chem. Int. Ed. 2006, 45, 4167-4172; c) R. B. Keithley, A. S. Rosenthal, D. C. Essaka, H. Tanaka, Y. Yoshimura, M. M. Palcic, O. Hindsgaul, N. J. Dovichi, Analyst 2013, 138, 164-170.

[6] a) A. K. Yadav, D. L. Shen, X. Shan, X. He, A. R. Kermode, D. J. Vocadlo, J. Am. Chem. Soc. 2015, 137, 1181-1189; b) I. M. Ivanova, S. A. Nepogodiev, G. Saalbach, E. C. O'Neill, M. D. Urbaniak, M. A. J. Ferguson, S. S. Gurcha, G. S. Besra, R. A. Field, Carbohydr. Res. 2017, 438, 26-38.

[7] a) C. R. Bertozzi, L. L. Kiessling, Science 2001, 291, 2357-2364; b) T. Feizi, W. Chai, Nat. Rev. Mol. Cell Biol. 2004, 5, 582-588; c) F. T. Liu, G. A. Rabinovich, Nat. Rev. Cancer 2005, 5, 29-41; c) Y. Yang, T. W. Jia, F. Xu, W. Li, S. Tao, L.-Q. Chu, Y. He, Y. Li, Y. S. S. Iyer, P. Yu, ACS Appl. Nano Mater. 2018, 1, 1058-1065.

[8] a) M. H. Lee, J. H. Han, P.-S. Kwon, S. Bhuniya, J. Y. Kim. J. L. Sessler, C. Kang, J. S. Kim, J. Am. Chem. Soc. 2012, 134, 1316-1322; b) W.-T. Dou, Y. Zhang, Y. Lv, J. Wu, Y. Zang, C. Tan, J. Li, G.-R. Chen, X. P. $\mathrm{He}$, Chem. Commun. 2016, 52, 3821-3824; c) M. Wahiba, X. Q. Feng, Y. Zang, T. D. James, J. Li, G.-R. Chen, X. P. He, Chem. Commun. 2016, 52, 11689-11692; d) W.-T. Dou, Y. L. Zeng, Y. Lv, J. Wu, X.-P. He, G.R. Chen, C. Tan, ACS Appl. Mater. Interfaces 2016, 8, 13601-13606; e) Q. Zhang, Y. Cai, X.-J. Wang, J.-L. Xu, Z. Ye, S. Wang, P. H. Seeberger, J. Yin, ACS Appl. Mater. Interfaces 2016, 8, 33405-33411; f) L. Liu, Z. Ruan, T. Li, P. Yuan, L. Yan, Biomater. Sci. 2016, 4, 1638-1645; g) N. Shivran, M. Tyagi, S. Mula, P. Gupta, B. Saha, B. S. Patro, S. Chattopadhyay, Eur. J. Med. Chem. 2016, 122, 352-365; h) H.-H. Han, C.-Z. Wang, Y. Zang, J. Li, T. D. James, X. P. He, Chem. Commun. 2017, 53, 9793-9796; i) Q. Zhang, Y. Cai, Q.-Y. Li, L.-N. Hao, Z. Ma, X.-J. Wang, J. Yin, Chem. Eur. J. 2017, 23, 14307-1431; j) P. Kesavan, V. Pandey, M. K. Raza, S. Mori, I. Gupta, Bioorg. Chem. 2019, 91, 103139; k) N. E. M. Kaufman, Q. Meng, K. E. Griffin, S. S. Singh, A. Dahal, Z. Zhou, F. R. Fronczek, J. M. Mathis, S. D. Jois, M. G. H. Vicente, J. Med. Chem. 2019, 62, 3323-3335.

[9] a) K. Y. Zhang, K. K.-S. Tso, M.-W. Louie, H.-W. Liu, K. K.-W. Lo, Organometallics 2013, 32, 5098-5102; b) T. Papalia, G. Siracusano, I. Colao, A. Barattucci, M. C. Aversa, S. Serroni, G. Zappala, S. Campagna, M. T. Sciortino, F. Puntoriero, P. Bonaccorsi, Dyes Pigments 2014, 110, 67-71; c) D.-T. Shi, D. Zhou, Y. Zang, J. Li, G.-R. Chen, T. D. James, X. P. He, H. Tian, Chem. Commun. 2015, 51, 3653-3655; d) C. S. Wong, 
S. Hoogendoorn, G. A. van der Marel, H. S. Overkleeft, J. D. C. Codee, ChemPlusChem 2015, 80, 928-937; e) E. Calatrava-Perez, S. A. Bright S. Achermann, C. Moylan, M. O. Senge, E. B. Veale, D. C. Williams, T. Gunlaugsson, E. M. Scanlan, Chem. Commun. 2016, 52, 13086-13089 f) A. L. Nguyen, K. E. Griffin, Z. Zhou, F. R. Fronczek, K. M. Smith, M. G. H. Vicente, New. J. Chem. 2018, 42, 8241-8246.

[10] a) L. Dong, Y. Zang, D. Zhou, X.-P. He, G.-R. Chen, T. D. James, J. Li, Chem. Commun. 2015, 51, 11852-11855; b) F. Liu, P. Tang, R. Ding, L. Liao, L. Wang, M. Wang, J. Wang, Dalton Trans. 2017, 46, 7515-7522.

[11] a) A.;Louret, K. Burgess, Chem. Rev. 2007, 107, 4891-4932; b) R. Ziessel, G. Ulich, A. Harriman, New J. Chem. 2007, 31, 496-501; c) G. Ulrich, R. Ziessel, A. Harriman, Angew. Chem. Int. Ed. 2008, 47, 11841201.

[12] a) D. Fahy, M. N. M. E. Sanad, K. Duscha, M. Lyons, F. Liu, P. Bozhkov, H.-H. Kunz, J. Hu, H. E. Neuhaus, P. G. Steel, A. Smertenko, Sci. Rep. 2017, 7, 39069; b) S. C. Alexander, K. N. Busby, C. M. Cole, C. Y. Zhou, N. K. Devaraj, J. Am. Chem. Soc. 2015, 137, 12756-12759; c) J. Yang, J. Seckute, C. M. Cole, N. K. Devaraj, Angew. Chem. 2012, 124, 7594 7597; Angew. Chem. Int. Ed. 2012, 51, 7476-7479; d) N. K. Devaraj, S. Hilderband, R. Upadhyay, R. Mazitschek, R. Weissleder, Angew. Chem. 2010, 118, 2931-2934; Angew. Chem. Int. Ed. 2010, 49, 2869-2872.

[13] a) M. L. Agazzi, M. B. Ballatore, A. M. Durantini, E. N. Durantini, A. C. Tomé, J. Photochem. Photobiol. C: Photochem. Rev. 2019, 40, 21-48; b) S. Kolemen, E. U. Akkaya, Coord. Chem. Rev. 2018, 354, 121-134; c) T. Kowada, H. Maeda, K. Kikuchi, Chem. Soc. Rev. 2015, 44, 4953-4972.

[14] a) K. Villadsen, M. C. Martos-Maldonado, K. J. Jensen, M. B. Thygesen, ChemBioChem 2017, 18, 574-612; b) X.-P. He, Y.-L. Zeng, Y. Zang, J. Li, R. A. Field, G.-R. Chen, Carbohydr. Res. 2016, 429, 1-22.

[15] M. M. Nielsen, C. M. M. Pedersen, Chem. Rev. 2018, 118, 8285-8358.

[16] M. Schelhaas, H. Waldmann, Angew. Chem. 2006, 108, 2192-2219; Angew. Chem. Int. Ed. 1999, 35, 2056-2083.

[17] a) A. M. Gómez, Reaction at Oxygen Atoms in Glycoscience (Eds.: B. Fraser-Reid, K. Tatsuta, J. Thiem) Springer-Verlag Berlin, $2^{\text {nd }}$ Ed. 2008 pp 103-177; b) A. Lipták, A. Borbás, I. Bajza, Protecting Group Manipulations in Carbohydrate Synthesis in Comprehensive Glycoscience. From Chemistry to Systems Biology. (Ed.: J. P. Kamerling) Elsevier, 2007, p.p. 203-259. Ch. 1.06; c) S. Oscarson, Protective Group Strategies in The Organic Chemistry of Sugars; (Eds. D. E. Levy, P. Fügedi); Taylor \& Francis Group LLC: Boca Raton, 2006 Ch. 3.

[18] a) N. K. Kochetkov, Tetrahedron 1987, 43, 2389-2436; b) N. K. Kochetkov, A. J. Khorlin, A. F. Bochkov, Tetrahedron Lett. 1964, 5, 289-293.

[19] 1,2-MeOEs are readily available by reaction of per-O-acylated pyranosyl bromides with methanol in the presence of anhydrous sodium bicarbonate, according to S. Wei, J. Zhao, H. Shao, Can. J. Chem. 2009 87, 1733-1737.

[20] (a) C. Uriel, J. Ventura, A. M. Gómez, J. C. López, B. Fraser-Reid, Eur. J. Org. Chem. 2012, 3122-3131. (b) C. Uriel, J. Ventura, A. M. Gómez, J. C. López, B. Fraser-Reid, J. Org. Chem. 2012, 77, 795-800. (c) C. Uriel, P. Rijo, A. S. Fernandes, A. M. Gómez, B. Fraser-Reid, J. C. López, Chemistry Select 2016, 1, 6011-6015.

[21] M. del Río, F. Lobo, J. C. López, A. Oliden, J. Bañuelos, I. López-Arbeloa, I. Garcia-Moreno, A. M. Gómez, J. Org. Chem. 2017, 82, 1240-1247.

[22] R. I. Roacho, A. J. Metta-Magaña, E. Peña-Cabrera, K. H. Pannell, J. Phys. Org. Chem. 2013, 26, 345-351.

[23] Y. Gabe, T. Ueno, Y. Urano, H. Kojima, T. Nagano, Anal. Bioanal. Chem. 2006, 386, 621-626.

[24] For related access to 4,4'-dialkoxy BODIPYs, see: a) A. L. Nguyen, P. Bobadova-Parvanova, M. Hopfinger, F. R. Fronczek, K. M. Smith, M. G H. Vicente, Inorg. Chem. 2015, 54, 3228-3236; b) A. M. Courtis, S. A. Santos, Y. Guan, J. A. Hendricks, B. Ghosh, D. M. Szantai-Kis, S. A. Reis, J. V. Shah, R. Mazitschek, Bioconjugate Chem. 2014, 25, 1043-1051; c) B. Brizet, C. Bernhard, Y. Volkova, Y. Rousselin, P. D.
Harvey, C. Goze, F. Denat, Org. Biomol. Chem. 2013, 11, 7729-7737; d) C. Tahtaoui, C. Thomas, F. Rohmer, P. Klotz, G. Duportail, Y. Mely, D. Bonnet, M. Hibert, J. Org. Chem. 2007, 72, 269-272.

[25] E. V. Rumyantsev, S. N. Alyoshin, Y. S. Marfi, Inorg. Chim. Acta 2013, 408, 181-185.

[26] a) T. Zhang, C. Ma, T. Sun, Z. Xe, Coord. Chem. Rev. 2019 390, 76-85; b) J. Ahrens, B. Cordes, R. Wicht, B. Wolfram, M. Bröring, Chem. Eur. J. 2016, 22, 10320-10325; c) L. G. Meimetis, E. Boros, J. C. Carlson, C. Ran, P. Caravan, R. Weissleder, Bioconjugate Chem. 2016, 27, 257-263.

[27] In this context, owing to its highest reactivity, the "simplest" unsubstituted BODIPY dye could only be obtained years after the first BODIPY derivative was described by Treibs and Kreuzer, in 1968. See, a) A. Treibs, F.-H. Kreuzer, Justus Liebigs Ann. Chem. 1968, 718, 208-223; and b) I. J. Arroyo, R. Hu, G. Merino, B. Z. Tang, E. Peña-Cabrera, J. Org. Chem. 2009, 74, 5719-5722; c) A. Schmitt, B. Hinkeldey, M. Wild, G. Jung, J. Fluoresc. 2009, 19, 755-758; d) K. Tram, H. Yan, H. A. Jenkins, S. Vassiliv, D. Bruce, Dyes Pigments 2009, 82, 392-395.

[28] a) I. García-Moreno, A. Costela, L. Campo, R. Sastre, F. Amat-Guerri, M. Liras, F. López Arbeloa, J. Bañuelos Prieto, I. López Arbeloa, J. Phys. Chem. A 2004, 108, 3315-3323; b) S. Mula, A. K. Ray, M. Banerjee, T. Chaudhuri, K. Dasgupta, S. Chattopadhyay, J. Org. Chem. 2008, 73, 2146-2154.

[29] I. V. Aksenova, R. T.Kuznetsova, E. N. Tel'minov, G. V: Mayer, E. V. Antina, M. B. Berezin, Russ. J. Phys. Chem. 2016, 90, 349-355.

[30] E. Bodio, C. Goze, Dyes Pigments 2019, 160, 700-710.

[31] L. Yang, R. Simionescu, A. Lough, H. Yan, Dyes Pigments 2011, 91, 264-267.

[32] a) L. Li, B. Nguyen, K. Burgess, Bioorg. Med. Chem. Lett. 2008, 18, 3112-3116; b) G. Duran-Sampedro, I. Esnal, A. R. Agarrabeitia, J. Bañuelos Prieto, L. Cerdán, I. García-Moreno, A. Costela, I. LopezArbeloa, M. J. Ortiz, Chem. Eur. J. 2014, 20, 2646-2653; c) A. L. Nguyen, F. R. Fronczek, K. M. Smith, M. G. H. Vicente, Tetrahedron Lett. 2015, 56, 6348-6351.

[33] a) M. Wang, M. G. H. Vicene, D. Mason, P. Bobadova-Parvanova, ACS Omega 2018, 3, 5502-5510; b) A. L. Nguyen, M. Wang, P. BobadovaParvanova, Q. Do, Z. Zhou, F. R. Fronczek, K. M. Smith, M. G. H. Vicente, J. Porphyrins Phthalocyanines 2016, 20, 1409-1419.

[34] For an overview of the reactivity of the BODIPY core, including its reactivity, at C-2 and C-6, toward electrophilic reagents, see: a) N. Boens, B. Verbelen, W. Dehaen, Eur. J. Org. Chem. 2015, 6577-6595; b) N. Boens, B. Verbelen, M. J. Ortiz, L. Jiao, W. Dehaen, Coord. Chem. Rev. 2019, 399, 213024.

[35] Compound 10, was prepared according to our methodology (Ref. 21), in a one-pot procedure from isophthalide and 2,4-dimethyl-3-ethyl pyrrole. See also: A. Oliden, R. Sola-Llano, J. Bañuelos, I. García-Moreno, C. Uriel, J. C. Lopez, A. M. Gomez, Front. Chem. 2019, 7, 801.

[36] Protecting groups. Strategies and Applications in Carbohydrate Chemistry. (Ed.: S. Vidal) Wiley-VCH: Weinheim, 2019.

[37] M. Yu, J. K.-H. Wong, C. Tang, P. Turner, M. H. Todd, P. J. Rutledge, Beilstein J. Org. Chem. 2015, 11, 37-41.

[38] a) J. O. Huh, Y. Do, M. H. Lee, Organometallics 2008, 27, 1022-1025; b) G. Meng, S. Velayudham, A. Smith, R. Luck, H. Liu, Macromolecules 2009, 42, 1995-2001; A. Koscun, E. U. Akkaya, Tetrahedron Lett. 2004, 45, 4947-4949.

[39] a) R. R. Schmidt, K.-H. Jung, in Preparative Carbohydrate Chemistry, (Ed.: S. Hanessian) Marcel-Dekker: New York, 1997, pp. 283-312; b) R. R. Schmidt, W. Kinzy, Adv. Carbohydr. Chem. Biochem. 1994, 50, $21-$ 123.

[40] a) J. D. C. Codeé, R. E. J. N. Litjens, L. J. van den Bos, H. S. Overkleeft, G. A. van der Marel, Chem. Soc. Rev. 2005, 34, 769-782; b) P. J. Garegg, Adv. Carbohydr. Chem. Biochem. 1997, 52, 179-266; c) P. Fügedi, P. J. Garegg, H. Loenn, T. Norberg, Glycoconj. J. 1987, 4, 97-108.

[41] H. Paulsen, Angew. Chem. 1982, 94, 184-201; Angew. Chem. Int. Ed. 1982, 21, 155-224. 
[42] a) M. Mach, U. Schlueter, F. Mathew, B. Fraser-Reid, K. C. Hazen. Tetrahedron 2002, 58, 7345-7354; b) B. Fraser-Reid, J. C. López, Orthoesters and Related Derivatives in Handbook of Chemical Glycosylation (Ed.: A. V. Demchenko) Wiley-VCH: Weinheim, 2008; pp. 381-416.

[43] a) B. Fraser-Reid, J. C. López, pp. 1-29 in Ref. 1d; b) D. R. Mootoo, P Konradsson, U. Udodong, B. Fraser-Reid, J. Am. Chem. Soc. 1988, 110, 5583-5584.

[44] K. N. Jayaprakash, B. Fraser-Reid, Org. Lett. 2004, 6, 4211-4214.

[45] J. C. López, A. M. Gómez, C. Uriel, B. Fraser-Reid, Tetrahedron Lett. 2003, 44, 1417-1420.

[46] J. D. C. Codée, R. E. J. N. Litjens, R den Heeten, H. S. Overkleeft, J. H. van Boom, G. A. van der Marel, Org. Lett. 2003, 5, 1519-1522.

[47] F. Roussel, M. Takhi, R. R. Schmidt, J. Org. Chem. 2001, 66, 8540-8548.

[48] There are literature examples on the stability of substituted BODIPYs under hydrogenation conditions, see: a) $\mathrm{H}$. Sunuhara, $\mathrm{Y}$. Urano, $\mathrm{H}$. Kojima, T. Nagano, J. Am. Chem. Soc. 2007, 129, 5597-5604; b) D. P. Kennedy, C. M. Kormos, S. C. Burdette, J. Am. Chem. Soc. 2009, 131, 8578-8586; c) T. Komatsu, Y. Urano, Y. Fujikawa, T. Kobayashi, H. Kojima, T. Terai, K. Hanaoka, T. Nagano, Chem. Commun. 2009, 7015-7017.

[49] a) J. C. López, A. Agocs, C. Uriel, A. M. Gómez, B. Fraser-Reid, Chem. Commun. 2005, 5088-5090; b) C. Uriel, A. Agocs, A. M. Gómez, J. C: López, B. Fraser-Reid, Org. Lett. 2005, 7, 4899-4902; c) C. Uriel, A. M. Gómez, J. C. López, B. Fraser-Reid, Org. Biomol. Chem. 2012, 10, 8361-8370.

[50] F. López Arbeloa, J. Bañuelos , V. Martínez , T. Arbeloa, I. López Arbeloa, Int. Rev. Phys. Chem. 2005, 24, 339-374. 


\section{Entry for the Table of Contents}

Layout 2:

\section{FULL PAPER}

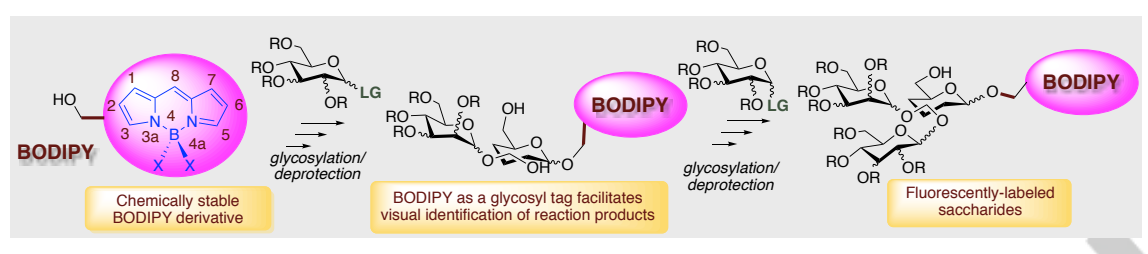

Boron-dipyrromethene (BODIPY) fluorophores, conveniently substituted, are able to endure most of the reaction conditions involved in synthetic sequences leading to oligosaccharides. Thus, BODIPY dyes could be used as aglycons in synthetic routes leading to fluorescently-labeled saccharides. Accordingly, they could display a dual role: as colorful glycosyl-tags during the synthesis, and as fluorescent-labels on the ensuing glycosides. The resulting BODIPY-labeled saccharides displayed remarkable fluorescence-efficiency in water, reaching quantum yield values up to $82 \%$, as well as notable lasing efficiencies and photostabilities.
Clara Uriel, Caterina Permingeat, Juan Ventura, Edurne Avellanal-Zaballa, Jorge Bañuelos*, Inmaculada GarcíaMoreno, Ana M. Gómez* and J. Cristobal Lopez*

Page No. - Page No.

BODIPYs as chemically stable fluorescent tags on synthetic glycosylation strategies towards fluorescently-labeled saccharides 